Portland State University

PDXScholar

$1-1-1982$

\title{
A study of the effects of active participation in instruction upon learning
}

Jerry D. Pratton

Portland State University

Follow this and additional works at: https://pdxscholar.library.pdx.edu/open_access_etds Let us know how access to this document benefits you.

\section{Recommended Citation}

Pratton, Jerry D., "A study of the effects of active participation in instruction upon learning" (1982). Dissertations and Theses. Paper 775.

https://doi.org/10.15760/etd.775

This Dissertation is brought to you for free and open access. It has been accepted for inclusion in Dissertations and Theses by an authorized administrator of PDXScholar. Please contact us if we can make this document more accessible: pdxscholar@pdx.edu. 


\title{
A STUDY OF THE EFFECTS OF
}

ACTIVE PARTICIPATION IN INSTRUCTION UPON LEARNING

\author{
By \\ JERRY D. PRATTON
}

A dissertation submitted in partial fulfillment

of the requirements for the degree of

DOCTOR OF EDUCATION

in

PUBLIC SCHOOL ADMINISTRATION AND SUPERVISION

Portland State University

University of Oregon

1982 
TO THE OFFICE OF GRADUATE STUDIES AND RESEARCH:

The members of the committee approve the dissertation

of Jerry D. Pratton, presented November 19, 1982.

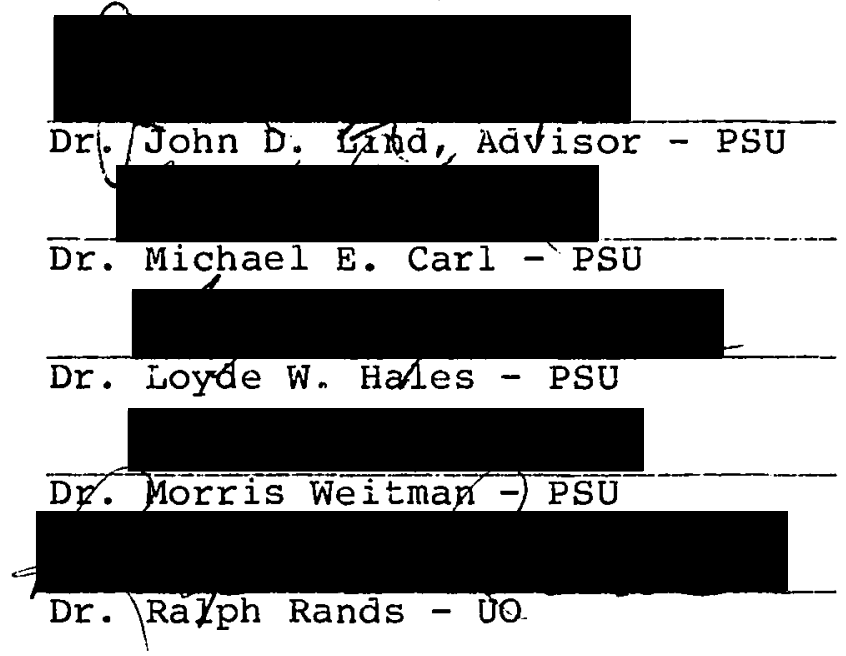

APPROVED :

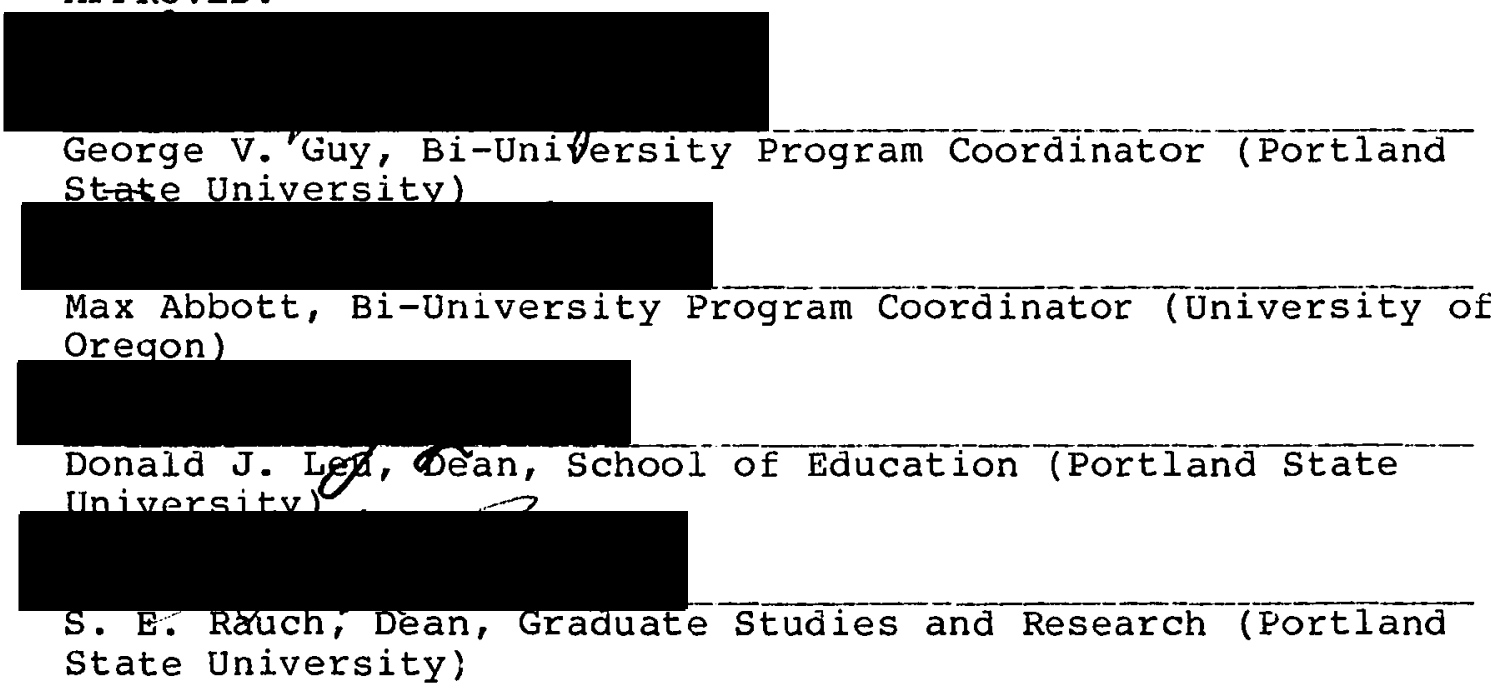


AN ABSTRACT OF THE DISSERTATION OF Jerry D. Pratton for the Doctor of Education in Public School Administration and Supervision presented November 24, 1982.

Title: A Study of the Effects of Active Participation Upon Learning
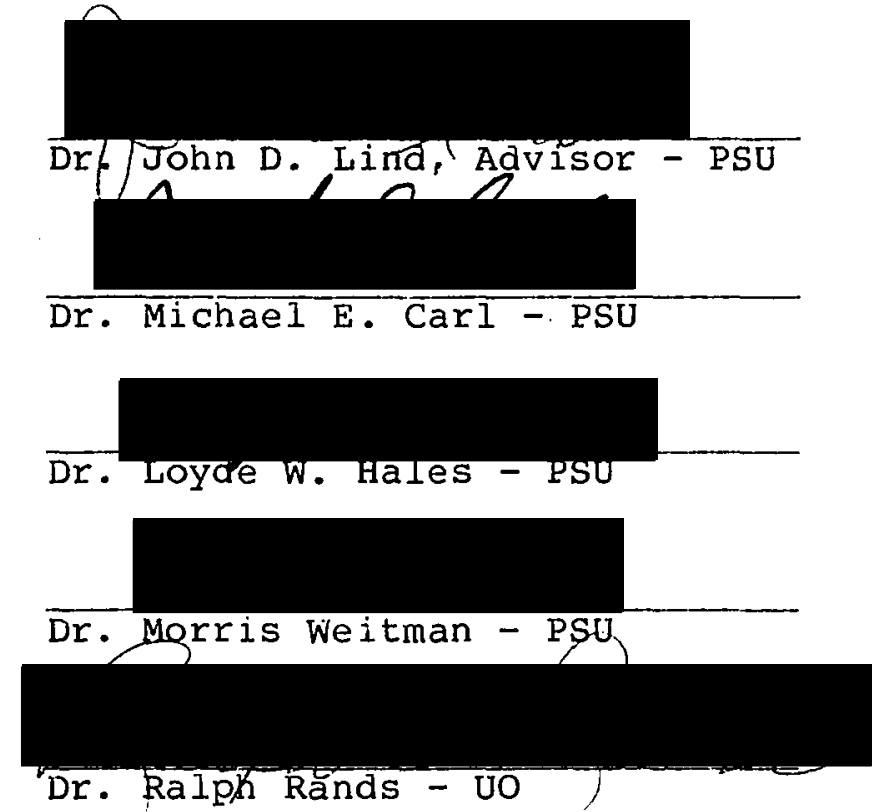

An experimental study of the effects of active participation on student learning was conducted with two levels of treatment of the independent variable. Intact groups were used because it was reasoned that results generated in classroom settings would likely be more generalizable to other classroom settings. 
The study was conducted in a medium-sized suburban school district mainly residential in character.

Five project teachers were trainer to teach a lesson on simple probability. Each teacher taught four lessons to fifth grade classes, two with Treatment I lactive student participation) and two with Treatment II (no active student participation). The lessons were alike in all possible respects except the treatment.

Immediately upon completion of instruction the students were administered a 15-item multiple choice posttest. The lesson and posttest were both researcher-developed instruments. The instruction and testing lasted about one hour for each class. The total number of students was 447 . The research hypothesis for the study was that the posttest mean of classes taught with active participation would be greater than che posttest mean of classes taught without active participation. The statistical hypothesis was stated as $\mu_{1}=\mu_{2}$.

The results of a t-test were found to be statistically significant at the .05 level causing the statistical hypothesis to be rejected and the research hypothesis to be accepted.

From this study, it appears that teaching is more effective when active student participation is incorporated 
into the teaching method. Additional research is recommended to test the retention of the effect and to test the effect with different age groups. 
To my lovely and patient wife, Norah, and my very special daughter, Pamela 


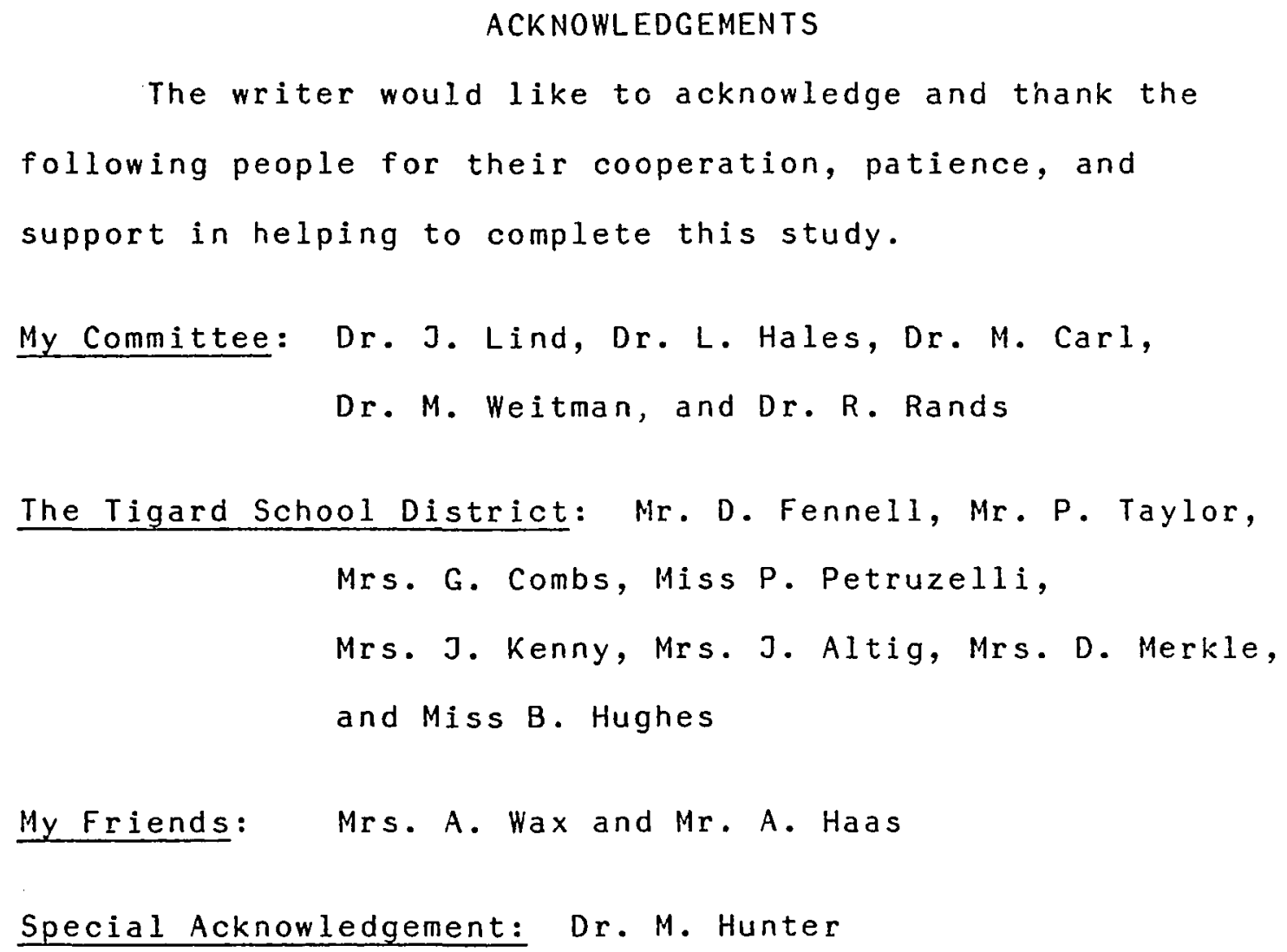


TABLE OF CONTENTS

Page

DEDICATION........................... ii

ACKNOWLEDGEMENTS....................... iv

LIST OF TABLES........................ vii

Chapter

I INTRODUCTION TO THE STUDY............ 1

Purpose of the study.............. 8

II REVIEW OF THE LITERATURE............. 12

Contemporary Trends.............. 20

The Etfects of Teaching........... 29

summary.................... 37

II METHODS AND PROCEDURES............. 39

Introduction................ 39

Research Design................ 40

Sampling Considerations........... 42

Selection and Assignment of Teacher... 43

Training Procedures............. 44

Instrumentation................ 50

The Lesson................ 50

The Posttest............... 52

Teaching Consistency......... 53

Field Testing.............. 53

Data Gathering Procedures...... 54

Data Analysis Procedures.......... 56

IV PRESENTATIONS AND ANALYSIS OF DATA...... 58

Sample................... 58

Presentation of Tabulation of Data

by class................. 59

Comparison of Treatment Levels....... 62

Analysis of Lesson Presentation...... 63

Comparison of Lesson Time...... 66

Comparison of Class

Characteristics...........6 69 
V CONCLUSIONS AND RECOMMENDATIONS........ 73

Research Outcomes............... 73

The Research Design............. 76

Limitations..................... 79

Implications for the Classroom...... 82

Implications for Research......... 83

Summary.................... 84

BIBLIOGRAPHY....................... 86

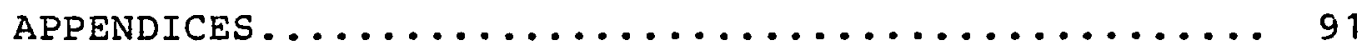

Appendix A - Project Lesson............... 92

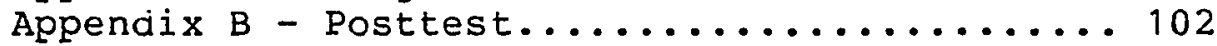

Appendix C - Bias Criteria................ 108

Appendix D - Parent Letter............... 112

Appendix E - Observation of Bias Survey

Treatment I................ 115

Appendix F - Observation of Bias Survey

Treatment II............. 117 
LIST OF TABLES

Table

Page

I Random Assignment of Classes to

Teachers and Method............ 45

II Table of Posttest Specifications...... 48

II Means, Standard Deviations, Variance, Degrees of Freedom and student t-Test Between Treatment Groups $I$ and $I I \ldots \ldots \ldots \ldots \ldots \ldots \ldots \ldots$

IV Means, Standard Deviation, Variance, and Frequency Distributions of Scores by Class within Treatment I................

V Means, Standard Deviation, Variance, and Frequency Distributions of Scores by Class Within Treatment II................

VI Observation Results of Bias Criteria Survey.................... 65

VII Time Duration for Project Lessons..... 67

VIII Means, Standard Deviation, Variance, and student $t$-Test for $T$ ime, in Minutes, for Project Lessons......

IX Class Enrollment and Class Attendance for Active Participation and NonActive Participation Groups....... 
CHAPTER I

INTRODUCTION TO THE STUDY

The fiela of education is taced with many difficult problems. A major one is the perception by the public as well as some researchers that teachers are ineffective and that education does not make a difference in the quality of student learning. The Phi Delta Kappan in its tenth annual Gallup poll of the public's attitudes toward public schools has pointed out that people want better teachers, improved curriculum, and higher standards.

For school officials, these polls are important in at least two ways. They alert decision makers to overall public reaction to a variety of school programs and policies. And they serve as a national benchmark against which local attitudes may be measured. (Gallup, 1978, p. 33)

In addition to low public esteem, education has sometimes been criticized from within its own ranks. For example, Levin (1977), in his article, "Educational Planning and Feaching-Learning strategies: The Notes of a Skeptic" said, "there is not much evidence that educational planners can implement new teacher-learner processes" (p. 10). Furthering the perception that teachers are ineffective are 
other researchers who "conclude that teaching methods do not seem to make a difference" and "there is hardly any direct evidence to favor one method over another" (Wollen and Travers, cited in Ebel, 1969, p. 1447). Siegel and Siegal stated: "it is generally discovered that students learn about as much when exposed to one kind of instructional environment as they do when exposed to another" (cited in Ebel, 1969 p. 1446). Stephens, Popham Jencks, Mosteller, and Moynihan have also drawn similar conclusions (Brophy, 1979 a, p. 5) This information must be both disturbing and confusing to educators.

If teaching does not make a difference on student learning, then why have the topics of effective teaching methods and techniques received so much attention in both literature and research? This paradox seems to raise a question: Do methods or techniques exist which if correctly applied will enhance the probability that a student will learn? And, if methods do exist, what are they?

Educators ought to be concerned that their efforts in the classroom are viewed by many as ineffectual. They should be able to justify their efforts by demonstrating effectiveness of the methods they use. Carefully conducted studies of teacher effectiveness in natural settings are needed to complement laboratory research . 
Behavioral science research methodology has reached a point in its development where, despite greater number of uncontrolled variables, rigorous studies conducted in natural settings should match if not surpass laboratory research (Hutt and Hutt, 1970, p. 71 ).

Dunkin and Biddle (1974) have similarly indicated the need for more field research concerning the improvement of teaching.

Therefore, it would appear that if educators were to improve their image and answer their critics they would need to prove their effectiveness in the classroom. To prove effectiveness, well designed and conducted studies in natural settings are needed. With a concern for how teaching is perceived by others as ineffective, with a desire to contribute empirical data in natural settings to the existing body of research, and with a belief that methods do exist which when applied by teachers positively or negatively affect student learning, this examiner has chosen to narrow the field of investigation to the relationship between teaching and learning. The situation is summarized as follows:

We believe that education needs less heat and more light. Educational problems will not be solved by heaping criticism on schools and teachers, or by advocating new ideas and techniques without showing that they really work. School administrators do not need further abuse; they need specific, data based information that will enable them to diagnose particular situations accurately and follow through with 'treatment' established as effective or at least probably effective in such situations. (Fedigan, 1979, p. 1) 
Teachers are faced each day by large groups of stirdents who have different learning styles, different learning rates, and different motivations; therefore, one of the critical dilemmas confronting teachers and administrators in education today is deciding which instructional method will be the most efficient and effective in order for stuaents to learn. To further complicate the task of a teacher, time and materials with which to instruct their classes are limited. In addition the teacher must somehow balance the needs and expectations of the students, the parents, the principal, the school board, and in many cases the community.

The questions for the teacher at this point are, "How can I instruct students so they learn well, and how can I teach efficiently and still leave time for other instruction?" The answer is to find the best method or plan for instruction and use it. However, in trying to answer these questions the teacher is presented with a new dilemma. Out of all the methods that are available and have been reresearched, which plan, method, or theory should be applied to promote the best learning results? Educational literature is saturated with different methods, plans, and theories for achieving more effective instruction. Jencks has concluaded "that teachers do not have important effects on students" (Cited in Brophy, 1979a, p. 5). On the other hand, Flanders has said "that pupils learning is affected 
by teacher influence in the classroom and that this infuence is established through verbal behaviors" (Cited in silvernail, 1979, p. 14). Medley (1975) through his studies believes that "teacher behavior does have influence over student growth" (p. 23). Since research findings are in conflict, educators remain confused about which methods are effective. For example, if both the heuristic (inquiry) method and the lecture method are effective, the question of which method to use still remains for the teacher. It is at this point, according to silvernail (1979), that teachers should begin looking at instructional methods in light of the students, the concept taught, and the best techniques to use. In summary, the problem remains that teachers have a broad range of theories from which to select; yet some of those theories have no substantial support in empirical research.

Another problem faces school administrators. Part of a school administrator's role is to help teachers with instructional decisions through staff development programs. with increasing parent expectations, greater student demands, and a strong movement for school accountabiity, those decisions concerning effective instruction are imperative (Mealey, 1975). The problem of iajentifying effective teaching is an important one because support for schools by their patrons is based upon accountability and credibility. If administrators and teachers do their jobs well, student 
learning is enhanced which in turn generates students success, positive morale and support for the school by patrons. To make good instructional decisions, administrators need current data and information about which specific methods of instruction enhance learning. Research concerning which specific instructional methods are effective can help administrators assist their teachers in selecting effective teaching methodologies.

Though there is little research support for specific instructional techniques, there is strong theoretical support for effective teaching. Hunter (1976) believes that teachers do make a difference in the learning outcomes of their students and that the elements of instruction which she has identified enhance student learning. Within her theoretical framework of the essential elements of instruction are (a) teaching to an objective, (b) selecting objectives at the correct level of difficulty, (c) monitoring and adjusting student progress toward objectives, and (d) employing principles of learning. She has stated some principles of learning which, when applied, she believes will increase the probability and efficiency of student learning. Some of her principles of learning are motivation, transfer, retention, and reinforcement. Within the principles of learning is a component called "active participation." 
Active participation is defined as the deliberate and conscious attempt on the part of the teacher to cause the students to participate overtly in the lesson. For example, if a teacher in presenting a lesson in division, asks the students to demonstrate their knowledge of how many digits are in the aividend by holding up the correct number of fingers or writing the number on their papers, the stuaents are overtly participating and the teacher has used active participation.

To further explain active participation as a technique employed by the teacher to enhance student learning, it is important to carefully examine what active participation requires the student to do as well as to clarity its rationale tor use. First, active participation provides a focal point for learning for the total class. Secondly, it involves overt student benavior such as writing, describing, or identifying. By involving the students overtly, their attention is more apt to be on the lesson. Thirdly, active participation provides practice for the student during the lesson while a concept is being developed. This practice also provides feedback for teachers so they may monitor and then make adjustments for student mistakes or misunderstandings rather than waiting until the lesson has been completed anà extenád practice assigned. And fourthly, active participation provides "time on task." This 1 s important for reasons pointea out in mastery learning theory (Bioom. 
1976). Bloom believes learning will be enhanced when the student has enough time to master the task. Bloom's mastery learning theory is discussed further in Chapter II.

The rationale for a teacher using active participation as a technique to encourage student learning is two-fold. If the same task is given to the class, if the students do not have a choice in whether to do the task or not, and if they have no choice as to which task they will learn, then learning will be both more uniform and more likely to occur. (Doyle, 1979) Also when a class is given a short term task and is actively participating individually or together, the likelihood of better classroom behavior will exist. (Evertson, 1978)

To summarize the problem, the Hunter (1976) method (Instructional Theory Into Practice) is a widely used method in need of supporting research. Within that method is a critical element known as active participation which, to the knowledge of the researcher has never been testea.

\section{Purpose of the Study}

This study is based on a belief by Hunter (1976) that teachers can make a difference in the learning of their students by enlisting certain methods. As Medley (1975) said, "Teacher behavior does have influence over student growth" (p. 23). The purpose of this study is to compare student learning outcomes under two conditions: with and without active participation. The main question addressed in this 
study 1s. Does the use of active particlpation positively efrect student learning? Ascertaining whether or not active participation makes a significant difference in the learning outcomes for students is deemed to be valuable information which could help teachers and school administrators make instructional decisions.

The second purpose of this study is to provide teachers and administrators with instructional information. It is possible for school principals to aid teachers by providing them with staff development programs concerning effective teaching techniques and methods in their schools. However, in oräer to heip instructional managers infiuence teachers with instructional decisions, administrators need sound eviaence to support their staff development programs. A third purpose of this study is to generate dara in the classroom. Experts such as Brophy (1979a) have said that it is important for studies to be conaucted in classroom environments. If resuits are to be used by teachers and administrators, then it is important that empirical data be collected in the same setting in which teachers and administrators must function. As Dunkin and Biddle (1974) have stated, "despite scores of published studies, evidence concerning the 'improvement' of teaching is not yet well established." (p. 133)

A Fourth purpose of this study is to add research information to the literature and together with other studies 
begin the roundation of a theoretical framework for effective instruction. As Mechner has said, "older, all-inclusive theories are gone as major psychological forces and have been replaced by minature systems describing specifics" (Cited in Ebel, 1969, p. 727). Justification for this study is based on a review of the literature ana on a genuine need in the field. Brophy and Patman have stated that "recent work suggests that classroom management skills correlate with student learning gains" (Brophy, 1979a, p. 11). In a review of recent research in this field, Mediey (1975) cited the soar and Soar study (1976) as "identifying three areas where teachers exercise controi: (1) control of pupil behavior, (2) control of choice of subject matter, and (3) control of thinking processes which pupils use" (p. 19). Niediey further emphasized that teacher education programs based on weak theory ana research, "coupled with the high cost of program development and the increasing concern by the public for accountability in education, leave no alternative to moving anead without dealing with this critical area" (1975, p. 31).

Considering the aforementioned purposes, it was reasoned that that a controlled experiment dealing with the relationship of teaching to learning woula yiela useful information for educators. This study specifies active participation as the independent variable and learning as the dependent variable. It was conducted in a suburban medium- 
sized unified school district; the subjects were fifth grade students from eight elementary schools. The hypothesis was that there will be a significant difference in student learning between classes taught with active participation and those taught without active participation. 


\section{CHAPTER II}

\section{REVIEW ${ }^{\circ}$ OF THE LITERATURE}

The study of the effects of teaching araws upon many years of theoretical development arid research in the larger field of instructional theory. Therefore, this investigator turned to both learning theory and teaching theory to provide a foundation for studying the effects of teaching. As one part of this chapter, emphasis will be placed on a brief development of the historical trends in teaching and learning theory.

Another emphasis in the literature review is devoted to recent trends in teaching theory development. Brophy $(1979 b)$ has synthesized the work in this field and developed a framework for further study. (p. 10)

Contributions from formal research are then examined for results and relevance to effective teaching. Parakh (1971) has said that about 2000 studies on the various aspects of instruction have been conducted with "inconclusive and meager results." Parakh further stated that studies should concentrate on "teacher behavior" and "immediate effects" (p. 171).

The final portion of this literature review is narrowed to a summary of effective teaching. Results are somewhat 
fragmented and theory development in the effects of teaching on learning is in its infancy. (Dunkin and Biddle, 1974)

In America during the 1800's and early 1900's little empirical data were available to support the prevalent notions and theories of the day. "Early developments in teaching methods were based on the need to organize classroom teaching as efficiently as possible" (Blishen, 1970, p. 755); and teachers were considered "good" if they maintained classroom discipline. (Silvernail, 1979, p. 12) Until the late 1700's the lecture was the method most widely used in classrooms.

About the beginning of the nineteenth century Pestalozzi decided instruction should have organization and rationale, and students should learn other than by strict recitation. Pestalozi respected students' interests and abilities and believed subject matter should be adjusted to student ability. Instruction was to proceed in natural progression from the simple to the complex. Pestalozi was one of the first methodologists to take students through object lessons from the concrete to the abstract. For example, students would be questioned about their informal impressions about as object such as a chair. Then later after further study and discussion students were to arrive at a formal definition or concept. (Butts and Cremin, 1953). 
Later educators systematized Pestalozi's methods. Sheldon, during the early $1800^{\prime}$ 's at Oswego State Normal School, adopted and furthered the Pestalozzian methods into a "more formalized and strict adherence of steps." (Butts and Cremin, 1953, p. 437).

Though Pestalozzi's methods were oriented toward the elementary school, Herbart's methods during the first half of the nineteenth century were more directed toward secondary and higher education. Herbart believed social intercourse gave students basic elementary ideas, and human experiences derived from classroom experiences developed concepts. Instruction was organized into five teaching steps: (1) preparation, (2) presentation, (3) association, (4) systemization, and (5) application. With these instructional steps it was the job of the teacher to build what Herbart termea the apperceptive mass out of a cluster of ideas and concepts. The notion was for the teacher to link ideas together and induce students to discuss matters related to the lesson. (Butts and Cremin, 1953)

By the late $1800^{\prime}$ 's educational methodology was just beginning to undergo some changes with Dewey who began his Laboratory School at the University of Chicago in 1898. Dewey believed it was important for students to participate in the complete act of thought, and subject matter ought to be organized in a psychological order of learning. In order to more fully determine the best learning sequence, Dewey, 
through his conceptualization of scientific method, used the Laboratory school to study teaching, students, and learning. From his studies, he deduced that students have various impulses: the social impulse, the constructive impulse, the investigative and experimental impulse, and the expressive impulse. These impulses were then to be used by the teacher in the instructional process to the students' best advantage. According to Mayhew and Edwards (1966), "The activity program [was the plan] through which Dewey sought to train youngsters in cooperative and mutually useful living. Self expression, cooperation, activity, experimentation, construction, play, and contact with nature became the watchwords of the new school" (p. 438).

Kilpatrick, one of Dewey's disciples, introduced yet another change in teaching methodology. Between 1915 and 1920, Kilpatrick developed the project method of instruction. He believed the base for teaching was learning, and learning was best achieved by doing. Teachers were to involve students in activities aimed at solving specific problems. (Butts and Cremin, 1953) This meant the teacher's role was to help students plan, execute, and evaluate their projects and work. Kilpatrick believed that in many cases it was more important for the teacher to possess good interpersonal skills rather than specific content knowledge of the student's project. 
Beginning in about the 1930's the "child development" movement began to take hold. (Silvernail, 1979, p. 13) The concept behind this approach was simply that education had been backwards in looking at teachers and how they taught rather than studying learners and how they learned. Instead, teachers were to observe how students learn, grow, and develop and adjust their methods accordingly. This "developmental" approach was the first to focus on the student and his/her psychological aspects. This was the "Dalton" period in educational methodology.

In 1953 Bloom advocated the "discussion method" which was designed to bring about more interaction between students and between the student and the teacher. It was thought this approach would stimulate higher levels of thinking and more creative thought.

The 1960's generally brought a renewed interest in the study of teaching and learning, and two more methods were advocated. The methods were quite similar in that they were both experimental by nature. Bruner advocated the "discovery method" in 1961, and suppes advocated the "Heuristic" approach in 1966. Both methods required students to investigate problems and generate solutions and alternatives, thus discovering the best answer or course of action. For example, Bruner believed the teacher should withhold concepts and principles from students that they were expected to learn. By giving the students instances 
and exemplars, they could then inauce concepts. This type of inquiry iearning has been widely used in recent years. Advocates of the various methodologies are saying that teachers, by controling the ciassroom method of instruction, can enhance the chance for learning to occur. Theorists believe, therefore, that teaching äoes make a difference in student learning. Teaching methods have been described as "patterns of teacher behavior that are recurrent, applicable to varous subject matter, characteristic of more than one teacher, relevant to learning, and applicable to more than one topic or specific objective" (Ebel, 1969, p. 1446). There are, however, educators who, having studiea these various methods, conclude that teaching methods do not make a difference in student learning. (Cited in Ebe1, 1963) Brophy stated in one of his most recent articles, "T'eacher Behavior and Its Effects," that "there do not appear to be any universal competencies (i.e., specific behaviors such as praising or asking higher level questions) that are appropriate in any and all teaching circumstances" (Brophy, 1979b, p. 9).

Gage of Stanford University, however, said that "although positive results remain hard to come by, some can be cited to indicate that, depending on which teaching methods are consiajered, they can make a difference in educational outcomes" (EbeI, 1969, p. 1447). 
Before discussing teacher effectiveness further, it is necessary to take into account some of the learning theories which were psychologically based. Previous attention in learning theory was focused on all-inclusive methodologies. This discussion will provide a transition from the teachercentered learning theories to student centered theories.

The learning process has also had a long and varied history, and in education many of the theories about how students learn began in the 1930's with Dalton and the child development movement. In order to investigate how children learn, researchers looked into the nature of the learner, his/her mind and motivations, and his/her general characteristics and reactions. Therefore, the study of learning generally fell into the realm of psychology. Probably the person with the largest early impact on learning theory was B. F. Skinner (1938). Skinner is famous for his work with reinforcement theory, but he also contributed to learning theory in the area of learning process and behavior. Collectively, the works of Skinner (1938) and Cronbach (1957) attempted to put together a scheme like this:

Learning Process

-reinforcement and extinction

--generalization

- -discrimination

- -attention

--punishment
Categories of Behavior -rote verbal learning --psycholinguistics - memory -concept learning --problem solving and thinking --perceptual-motor skill 
In 1966 Glasser further refined the design into what he called the psychology of learning and the design of instruction.

(1) The properties of specific behaviors and tasks for learning.

(2) The identification of learner characteristics.

(3) The identification of the context in which learning takes place and the task to be learned.

(4) The motivation of tudents to learn.

In his summary of teaching methods, Ebel (1969) cites nine dimensions of learning and instruction: (1) structure of learning process, (2) modeling, (3) learner behavior, (4) reward and punishment (5) moral development, (6) learner motives and emotions, (7) school and home relationships, (8) adaptability and (9) ego development.

However, these ideas were not always successful in explaining when learning is most effective. It has been concluded that "Lictie progress could be reported toward bridging the gap between laboratory psychology and the study of school learning" (Ebel, 1969, p. 726) Older theories which are all-inclusive are no longer used as major psychological concepts and have been replaced by subsystems identifying specifics (Mechner, 1967).

After a brief developmental review of learning and teaching theory, what is shown? It appears that neither learning theory nor teaching theory has successfully dis- 
closed the reasons or causes for effective learning. Both schools of thought have various components that have given insight into the learning process.

"In spite of the sharp increase of studies of classroom events, most recent research has focused on the activities rather than the effects of teaching. In terms of relationships between teacher behavior and pupil learning, our answers must be tentative" " (Dunkin and Biddle, 1974, p. 15). .

Yet, "as data accumulates, the influence of context is being recognized as more and more important" (Brophy, 1979b, p. 9). According to Dunkin and Biddle as well as Brophy, educational research is in its infancy and needs considerable more study specifically relating teacher behavior to learning. There are several studies and educational approaches that have merit theoretically and empirically when ued in the classroom; and these are addressed in the next sections.

\section{Contemporary Trends}

The early 1960's brought about a renewed interest in questions concerning what enhanced effective learning and effective teaching. People such as Medley and Mitzel, Soar, and Flanders were trying to identify what type of teaching created effective learning. (Cited in Silvernail, 1979, p. 12) To synthesize these early studies, generally four types of teaching models were identified: (1) social interaction, (2) information processing, (3) personal source, and (4) behavior modification. (Silvernail, 1979, 
p. 14) Two general modes of teaching were identified, and they were described as "direct" and "indirect" teaching. The "direct" mode employed methods of lecture and information processing, whereas the "indirect" mode dealt with discussion and discovery methods. These methods, coupled with findings from his interaction analysis, caused Flanders to postuate "that pupils learning is affected by teacher influence in the classroom and that this influence is established through verbal behavior" (Cited in silvernail, 1979, p. 14). Also, other studies by Medley (1975) prompted him to believe that "teacher behavior does have influence over student growth" (p. 23).

During the period of time Flanders was investigating teacher characteristics, there was a shift in several areas of research interest. Educational theorists and researchers began to abandon all-encompassing theories and models which failed to explain teaching-learning in the past and began to concentrate on more specific behaviors of both teachers and students. Theorists began to correlate teacher and student interaction in terms of learning and achievement. And lastly, theorists began to study teaching in its natural context, the classroom, rather than in an artificially constructed clinic or laboratory. As these areas were becoming more widely researched, specific and positive results began to emerge. Coleman, in his 1966 study of Equality of Educational Opportunity, maintains that "the quality of teachers 
show [sic] a stronger relationship to pupil achlevement than fracilities and materials." (Coleman, 1966, p. 22)

Although, variation in school averages of teachers' characteristics accounted for higher proportion of variation in student achievement than did all other aspects of the school combined, excluaing the student-body characteristics.

(p. 316)

Bennet (1978) quoted Brophy and Evertson who found

that opportunities for immediate practice of the skills, together with opportunity for immediate corrective feedback were very important. Thus, the most sucessful teachers, in terms of pupil gain, conducted group lessons by giving initial demonstrations and then quickly moving around having each student try out what has been demonstrated and providing feedback on an individual basis. (p. 135)

The summary of research related to effective teaching

is aptly sumnarized by Bennett (1978).

Etiective teaching is not simply a matter of implementing a small number of basic skills. Instead, effective teaching requires the ability to impiement a very large number of diagnostic, instructional, managerial, and therapeutic skills tailoring behavior in specific contexts and situations to the specific needs of the moment. In short, effective teaching involves the orchestration of a large number of factors, continually shifting teaching behavior, and responding to similarly shifting needs. ( $p .144)$

In addition, according to Ebel (1969), psychologists found "task analysis adds a new requirement to the study of learning" (p. 708). Tasks are unique to the classroom and cannot be arranged arbitrarily as they can for Laboratory study. However, these tasks must be ordered into a taxonomy of behavioral categories which learning theory provides. 
In a recent article, Silvernail (1979) summarized

several research studies and

... found that there were several factors involved with the teaching-learning act that had a direct effect on student achievement as a result of specific teacher behavior. They were (in isolation): (1) flexibility in teaching style, (2) feedback, (3) questioning strategies, (4) structuring activities (planning and active participation), (5) clarity (lesson organization), (6) task-oriented teaching, (7) enthusiasm, (8) rewards (individual) and (9) class climate (allowing for involvement, affiliation, and cohesiveness). (pp. 12-13)

Parakh (1971) reviewed previous literature on teaching. He found that since 1900 , about 2000 studies had been devoted to the various aspects of teaching. Parakh cites the Handbook of Research on Teaching as having narrowed the study of teaching into three major variables: (1) "Central variables" (which were described as the teachers), (2) "relevant variables" (which were described as the anteceojents of the central variables), and (3) "Site variables" (which were described as the situation and subject matter). (1971, p. 171) Parakh was in search of the characteristics of good teachers and a definition for good teaching. His search led him to the conclusion that previous studies were "inconclusive" and offered "meager results" (p. 172). He felt that what were needed in research were studies that focused on "teacher behaviors" and "immediate effects" ( $p$. $174)$

Hunter (1976) continued the notion that teachers were central to effective learning and she states: 
of the many factors critical to students' successful achievement in school, one of the most important is the professional competence of teachers. This competence is based on what a teacher does, not on what a teacher is. When teachers' plans are based on solid content and sound theory, then implemented with an artistry that incorporates fundamental principles of human learning, students will learn. If those principles of human learning are violated or neglected, learning will be impeded. ( $p .1$ )

Offering a different point of view, Good, Biddle, and Brophy collaborated to study this very question in their 1975 book, Teachers Make a Difference. They discovered that special programs did not make a difference and cited project "Head start" as an example. (p. 56) The children in project "Head Start" were not significantly different from other children in their learning outcomes. They also discovered "some teaching methods are more effective than others, even when the curriculum is identical" (Good, Biddle, and Brophy, 1975, p. 67). The conclusion that some methods are more effective had also been stated by Rosenshine and Furst and Dunkin and Biddle. An example of the phenomenon where curriculum is similar yet methods are different is the phonic word attack approach to reading as opposed to the less successful sight or whole-word approach to reading as reported by Chall. (Cited in Good, Biddle, and Brophy, 1975)

Good, Biddle, and Brophy, (1975) though not thoroughly convinced that teachers are the only factors in effective learning, do concede that "...teaching behaviors do not correlate very strongly with student outcome measures, but 
the fact that they usually correlate strongly enough to reach statistical significance in different studies conducted in various settings by separate investigators suggests that they are in fact related to student outcomes" (p. 58).

Soar (1972) drew a similar conclusion when he stated, "It seems clear that research using systematic observation has begun to identify classroom behavior which supports pupil growth" (p. 522). It is interesting to note that soar is one of the first researchers to discuss methods of research and data gathering in the teaching/learning environment. Here he has mentioned "systematic observation" as one method.

Research in education has not always maintained a high level of credibility. Sometimes research was performed in exacting and classical ways which did not fit the classroom setting. Sometimes research was done in a laboratory setting, and findings were not relevant to classrooms. At other times quasi-experimental procedures were used in classroom settings, but the data were not reliable. Brophy (1977) addressed this topic as it pertained to teachers and effective learning. His suggestions on this topic are important to this investigator's study. First, Brophy suggested "methods of achieving compromise between classical laboratory settings and natural settings" was necessary. (1977, p. 5) Secondiy, he suggests that short term outcome 
data were best achieved "through judicious selection of research settings" (1977, p. 6). Lastly, and most importantly, Brophy recommends that the treatment be kept as usual. "Usual" refers to the typical way a method would ordinarily be used in a normal classroom. In addition, Brophy (1977) says, "The more thorough the treatment, the more likely systematic implementation, but the less generailizeable to orainary teaching" (p. 8).

Much of the most recent work is iragmented rather than organized into a whole Iramework, thus making it difficult for educators to apply in real situations. It is important to mention the work of two prominent educators who have synthesized much of the contemporary knowledge into a workable format. Bloom (1977) and Hunter (1976) have made significant contributions through their work on the relationship of teaching to learning.

When considering Bloom and his theory of "mastery learning," it would also be necessary to mention Block and his work on this same subject.

In its [mastery learning theory] simplest form, his [John B. Carrol, 1963] model proposed that if each student was allowed the time he needed to learn to some level and he spent the required time, then he could be expected to attain the level. However, if the student was not allowed enough time, then the degree to which he could be expected to learn was a function of the ratio of the time actually spent in learning to the time

degree of learning $=\mathrm{f}$ (Block, 1971, p. 5) time actually spent time needed 
Block, (1971) believes that there is a relationship between aptitude and achievement for whole groups. Both variables in groups should be normally distributed. If a student is given enough time to learn something well, then the achievement curve will be skewed heavily to the right while aptitude obviously stays the same. (Block, 1971) Bloom, Block, and Carrol all indicate that most students in a typical school setting can learn well. (Bloom, 1976)

"Mastery learning represented a great advance over previous strategies in two important respects: (1) feedback was much improved, and (2) there were greater variety of instructional correctives" (Block, 1971, p. 7). In Human Characteristics and School Learning, Bloom (1976) outlines in great detail and complexity the notion of mastery learning theory. However, the important aspect to note was that mastery learning stressed teacher control and student involvement in the teaching-learning act; and that not only was achievement increased, but likewise so were several of the student affective areas. In his summary of mastery learning theory, Fedigan (1979) stated:

Studies of mastery learning and environmental effects have produced some results that converge with those from some of the recent process-product studies. The two types of research appears to differ most with respect to the broad questions they seek to answer. The product-product studies of classroom behavior are looking for what works best in classrooms as they currently function, 
while the learning environmentalists, and especially the mastery researchers, are studying changes in present classroom functioning intended to maximize achievement. (p. 101)

Another contributor to the field of educational theory was Hunter. Though for the most part her ideas were not new, she has concentrated on putting them into practice in a meaningful, theoretical framework. Her basic tenet was that learning is enhanced by efficient and effective teaching. Hunter (1976) believed that teacher behavior had definite effects, either positive or negative, on student learning and furthermore that the teacher ought to be both skilled and knowledgeable enough to consciously use those behaviors relative to the learning at hand.

In her theoretical Eramework Hunter (1976) had identified four major components that enhance the students' learning: (1) teaching to an objective, (2) setting objectives at the correct level of difficulty, (3) monitoring and adjusting the student learning, and (4) applying principles of learning (i.e., reinforcement theory, retention, motivation, etc.). Each of these components is very complex and requires specific relevant teacher behaviors which. The important idea was that good teachers are not just born. Teachers can be taught the skill of effective teaching. The point is simply that teaching can be made a science with a specific body of knowledge that is empirically supportable when selecting those behaviors which promote greater learning for students. (Hunter, 1976) 
The Effects of Teaching

The purpose of this section is to report the various research on the effects of teaching and to summarize the findings. There have been several recent studies advancing correlations between teaching and learning. Though the findings are limited to specific teacher behaviors, results not only add to the body of empirical data but also seem to indicate particular direction.

As pointed out earlier, Silvernail found nine components that had a "direct and positive effect on student achievement as a result of specific teacher behavior" as put forth in his 1979 article, "Teaching Styles as Related to Student Achievement: What Research Says to the Teacher." (p. 12) In addition to supporting the concept of the effects of teaching, two recently written dissertations should be mentioned. An Ohio state study of the "Effects of Teacher Modeling on the Subsequent Behavior of Students" by Westcott (1978) found that "teacher modeling alone may be an effective means for increasing peer encouragement. • .however, teacher modeling plus prompting may be a highly effetive means" for student achievement "especially for low skilled students" (p. 204).

Morgan developed a study on "Relationships Between Learner Characteristics and Instructional Methods in a Special Education Mini-Course on Individual Instruction" designed to find out how students (dependent or independent 
learners) performed in two different modes (individualized and conventional) of teaching. It was concluded that "dependent students in the conventional group achieved significantly better than dependent students in the individualized method" (Cited in Dissertation Abstracts International, 1977, p. 4287).

At this point, a chronological and systematic review of research focusing on the effect of teaching on learning is appropriate. In 1969, scott systematically observed teachers and found both effective and ineffective teachers to show objective and quantifiable behavioral differences "both in terms of structure and the quality of their behavior" (p. 15). Scott found that effective teachers could be differentiated from ineffective teachers in all settings using three strategies: (1) "Teaching episodes that lasted a longer period of time" were used by the more effective teacher. They "sustain their behavior longer in a more continuous flow without interruption or change in direction." (2) The more effective teacher attained goals because the goals were more clearly understood or defined. (3) And, the more effective teacher used more positive and less negative feeling tone with the students. (1969, p. 11)

In a two-year study by soar (1971) called project "Follow Through," 70 kindergarten and first grade students were observed in seven experimental groups and two control classrooms. The obervers were looking specifically for 
teachers' methods of control and student responses to these methods. A factor analysis was used and the findings suggest
that the teacher who feels pressure to give pupils greater freedom may minimize both structure and control by reacting to her own discomfort in ways that do not support pupil growth. It appears that greater aegrees of direction and structure are associated with greater amounts of growth in the simple cognitive objectives, but greater amounts of freedom and pupil self-direction are associated with more complex abstract kinds of growth. With these children, negative affect seems to have little impact, while positive affect is related to cognitive growth. (Soar, 1971, p. 7)

Soar has concluded that the teacher by his/her behavior has a very definite impact on the effectiveness of student learning.

In 1972, Measel and Mood studied 15 second grade classrooms using an 18-category verbal interaction system. The data was analyzed using the Spearman Rank Order, and significant positive correlations were found "between modes of teacher influence and use of cognitive levels" and "between teacher cognition and that of pupils." (p. 99) These correlations were significnatly higher at Bloom's lower levels of thinking. Results caused Measel and Mood to conclude that teacher behavior can raise student thinking to Bloom's upper levels.

Bugbee, trained teachers to use two modes of teaching and then asked them to teach some ten-minute lessons to groups of the same age "Head start" children. The two modes 
were (1) giving information to the group and (2) questioning individuals in the group. The teachers were given additional training in observing, classifying, and modifying their own teacher behavior.

Results indicated that despite individual variability the teachers were quite effective in altering their behaviors on the experimental variable. They exhibited a high level of performance both in producing their assigned modes and in shifting from one distinct mode to another. (Bugbee, 1974, p. 10)

The Bugbee study is noteworthy because it indicates that teachers can be effectively trained in the use of given methods, suggesting once again that what a teacher does can make a difference.

In a study done at the University of Washington by Anderson (1975), teacher-developed objectives clearly defined to the students significantly improved learning. The 54 psychology students were given all of the learning objectives for the term and were lectured and tested on those concepts. One of the important points in the study was that instruction could, by focusing on baseline data and treatment on difficult test items, develop sensitive within-class designs for the detection of treatment effects. (p. 1-9)

The Far West Laboratory undertook a research study authorized by Berliner $\left(1976_{a}\right)$ to inquire whether an ethnographic (descriptive anthropological) approach to the study of teaching could yield new insights into the 
teaching-iearning process. The study found 61 dimensions for comparing classrooms and teachers. Among those 61 dimensions were arilling (\#17), modeling (\#36), and monitoring (\#37). (Berliner, 1976, p. 29) These are noteworthy and mentioned because active participation, the treatment in question in this dissertation study, encompasses the three dimensions cited in the Berliner study.

In 1976, Elias and wheeler conducted a study on instructional and classroom activities as reported by teachers. They found that student growth in reading could be directly attributed to the teacher, as opposed to materiais, individualized programs, or teacher aides. The importance of this finding lies in the focus on the teacher as an agent for instructional growth.

Another 1976 study, conducted by McDonald, included seconä- and Eifth-grade students as a phase II followup on reading and math. The study usea 97 teachers and their students in 45 schools, spanning elght school districts. The critical quetions posea were: (1) Do teachers make a difference? (2) How much difference do they make? and (3) What do they do that makes a difference?

McDonald wrote:

The practical aspect of teaching is to describe teaching effectiveness. This requires that we state a desired effect--a desired change in children-and the actions which produce it. We must also describe social conditions under which these teaching actions occur, and how these actions and their effects vary as social 
conditions of teaching change.

This concept of teaching effectiveness implies that there may be many kinds of teaching effectiveness. Different teaching actions under different conditions may produce different effects. The immediate goal of research of teaching should be to produce empirically verified descriptions of such relations. (1976, p. 39)

Two promising findings were reported by McDonald (1976). They were (1) "procedures which increase the amount of direct instruction are related to increased improved pupil performance" and (2) "if the performance of students is not carefully monitored students may make a large number of errors which remain uncorrected" (pp. 41-42). These findings by McDonald also lend credibility to the use of active participation, the treatment in this study.

Berliner conducted a study in 1976 using teachers of second and fifth grade students. He identified 20 effective teachers and 20 less effective teachers. He then observed them as they taught both reading and math. The students were administered both pretests and posttests. The foci of the study were the intercelationships of curriculum and teaching behaviors. "The evidence to date," Berliner reported, "indicated that the development of a special sample of teachers, representing extreme groups on measures of effectiveness, can be very useful in the study of teaching" (1976b, p. 53)

In a report and analysis of four studies using data collected on Bloom's Taxonomy, Soar and Soar (1976) stated 
the "degree of agreement of results across various studies is not high" (p. 1). However, Soar did point out some findings he considered important. He concluded "the greatest pupil gain was associated with (1) intermediate amounts of teacher control...and (2) smalier amounts of work at higher cognitive levels" (1976, p. 1). Another finaing by soar points out that there are inany variables at play in the learning process which may not be school or teacher related. Soar stated, "Pupil socioeconomic status more often than other variables, interacted with classroom process." (p. 1).

Elliot, in a 1976 article in Interchange, described the Ford Teaching Project in the East Anglican region of the United kingdom in which 40 teachers were stuaied. The study generated 43 hypotheses concerning implementing the inquiry approach to teaching. Data were gathered to support sone of the hypotheses. The most relevant to this dissertation was hypothesis \#13. "The more able teachers are at selimonitoring in their classroom practice, the more likely they are to bring about fundamental changes in it" (p. 19).

A study done in 1978 by Ekstrom using 52 second grade and 42 fitth grade teachers in math and reading, focused on effective characteristics of teachers. The study suggested that four teacher characteristics were helpful to instruction: (1) cognitive style, (2) teacher attitude 
(level of aspiration), (3) teacher-pupil interaction, and (4) instructional activity.

Similar characteristics were identified by Evertson in 1978. Evertson's study included 1,614 junior students and 69 teachers of math and English. He found that successful teachers "emphasizeả class discussion, lectures, and drill, and spent less time using individualized techniques or individualized seatwork" (p. 310). The study also found that the successful teacher tended to have more interaction with his/her students and "tended to dominate patterns of interaction" (p. 311). Evertson stated, "It is clear that some teachers consistently produce greater student learning than others, and that certain teacher behaviors have consistent positive or negative relationships with learning outcomes" (p. 328). And, "it is clear that learning outcomes are closely related to variables like the amount of direct instruction received and the amount of time that students spend in academic tasks" (Evertson, 1978, p. 328). Evertson cited Rosenshine as another investigator who came to the same conclusion.

In an ethnographic study by Hickman (1980), involving 90 chilarren kindergarten through fifth-grade, the findings pointed to the teacher as the largest single influence in classroom learning. Hickman stated that stuaent "response were either permitted by, or facilitated by, or generated by the climate of the classroom" (p. 25). 
"The most powerful feature of classroom contexts was their manipulation by the teacher" (p. 1).

Koppelman's "Influence of Cognitive Style on Teaching Style" is an ethnographic study which was designed not to prove the existence of teacher characteristics and their differences but rather to suggest areas for subsequent empirical research. His study involved five teachers in grades four through six who were observed for a total of 24 hours. Koppelman stated, "There have been insufficient investigations of the influence (if any) of cognitive style to teaching" (1980, p. 4). However, he did suggest five areas for further study among which was "teacher directive" behavior that would likely bring about effective learning for students.

In a summary review of Iiterature on teacher effectiveness, Medley (1975) stressed the urgent need for moving ahead with research on this subject. He said, "the weakness of theory and research on which programs [teacher education programs] are not based, coupled with the high cost of program development and the increasing concern by the public for accountability in education, leave no alternative to moving ahead. . with this critical area" (p. 31).

\section{Summary}

Recent developments in educational research have demonstrated that there is conclusive empirical evidence re- 
lating specific behaviors to student learning (Brophy, $1979 \mathrm{~b})$. However, implications from the review of the Iiterature are many and varied. First, educators need to be aware of the theories that attempt to explain all teachingl learning circumstances. If there is some universal "law" of teaching and learning, it has not yet been discovered; and for the most part the all-encompassing theories have not worked. Secondly, educators need to begin to think more inductively towards theory development. In the past, educators have estabilshed generai concepts and tried to deduce specific rules to apply in particular circumstances. The literature suggests more study and research would produce reliable information which could be worked into a meaningful and accurate theoretical framework. 'This would encourage educators to scientifically investigate problems requiring understanding rather than explaining the teaching/learning phenomenon in terms of existing theories. And thirdy, study in classroom situations is necessary. If teachers are to apply educational knowledge in typical classrooms, then that is where findings must be generated.

It is accurate to state that stuaies of how teaching relates to learning--though making some gains--leave much research to be done. Brophy has studiea "management and learning." Bloom has studied "time and learning," and Gage has studied "modes of curriculum and learning." Yet, there are many areas that are relatively unstudied. The effects of active participation on learning is one of those areas. 


\section{CHAPTER III}

\section{METHODS AND PROCEDURES}

\section{Introduction}

This study may be classified in the general area of research on learning theory as it applies to methods of teaching, It investigated the specific question: Does the use of the technique of active participation by teachers result in an increase in student learning? As a result of a review of the literature, the investigator developed an expectation that the use of active participation by teachers will positively affect student learning. For reasons to be discussed later, a two-group posttest experimental design was employed with intact groups assigned to the two levels of the independent variable (active participation).

Information and topics relevant to the methodology and procedures used are presented within the following organizational structure: Introduction, Research Design, Sampling Procedures and Considerations, Selection and Assignment of Teachers, Training Procedures, Instrumentation, Data Gathering Procedures, and Data Analysis Procedures. 
Research Design

The research design is briefly described in this section, together with a rationale for the selection made. An experimental two-group posttest design was used to investigate the influence of one teaching strategy (active participation) on student achievement. There were two levels of the treatment variable: active student participation and no active student participation. The dependent variable was student achievement of the lesson objectives, as measured by an investigator-constructed criterion test administered immediately following instruction. The treatment consisted of a 30-minute lesson on probability taught by five teachers selected and trained for this project. Twenty intact groups (heterogeneous homeroom fifth-grade classes) were randomly assigned to treatment. Within treatment levels, teachers were ranajomly assigned to classes. The research hypothesis was that the mean class achievement in classes taught with active participation will be greater than the mean class achievement in classes taught without active participation $\left(\mathrm{H}_{1}: \mu 1>\mu_{2}\right)$. The alternate research hypothesis was that the mean class achievement of students in classes taught by active participation will be less than the mean class achievement in classes taught without active participation $\left(\mathrm{H}_{2}: \mu_{1}<\mu_{2}\right)$. The statistical hypothesis, therefore, was that there will 
be no difference between the mean of the class means taught by active participation and the mean of the class means taught without active participation $\left(\mathrm{H}_{0}: \mu_{1}=\mu_{2}\right)$.

As indicated in the hypothesis, the sampling unit was the classroom with the measurement unit for analysis being the class mean (used as an individual score). An independent t-test was used to test the statistical hypothesis. A two-tailed test was used with alpha set at .05.

A number of factors influenced the decision to use the selected research design. (1) Field constraints mandated the use of intact groups. The typical practice of using student scores as data points results in a quasi-experimental design when intact groups are used. By using classrooms as a data points, this problem is allevaited (Glass \& Stanley, 1970). (2) Given the nature of the independent variable to be investigated, the teacher and the composition of the class are important variables. By using the class as the unit of measure and randomly assigning classes and teachers to method, greater control over these variables was obtained. (3) Two additional steps were taken to help control for the teacher variable. Five teachers were used. Each teacher was trained in the use of both methods and was monitored in her teaching for aaherence to the method. This monitoring process is described later in the text. (4) The intact classes were heterogeneous in composition. To 
control for variation among schools, random sampling was used.

\section{Sampling Procedures and Considerations}

The subjects used in this study were fifth-grade students from the Tigard School District, Tigard, Oregon. It is a medium-sized (5000-6000 students) suburban school district of average to slightly above average socio-economic level. The students were from eight elementary schools which range in size from 140 to 630 students. All of the 20 fifth-grade homeroom classes of the district were used, producing an available sample of approximately 500 students. Although students were not assigned at random to classes, the policy of the district to have heterogeneous classes was adhered to reasonably well in the various schools.

The decision to use 20 fifth-grade classes was partly the result of a desire to maximize within class heterogeneity and to minimize the heterogeneity among intact classes. Secondary students were not selected because at no point in the school day are secondary students of the same age together nor are they heterogeneously grouped. Thus, to find a heterogeneous grouping of homogeneous age children, the elementary school level was selected. Also, since it was not possible to randomly assign students to classes in order to obtain an experimental design, classes were used as the 
unit of measurement, thereby resulting in the need for a large number of subjects.

\section{Selection and Assignment of Teachers}

Another consideration was the teacher and her relationship with the students in the study. Since this investigator did not want the students influenced in any way by previous pupil-teacher relationships, homeroom teachers were not used as the project teachers. Teachers not known to the students were used in all cases. In this way, the study could exercise some control over, teaching effectiveness, style, and competence.

The investigator was aided in the selection of the project teachers by the principals of the participating schools and the staff development specialists of the district. The two major criteria employed in the selection of the project teachers were: (1) the teacher had knowledge of Hunter's elements of instruction and the principles of learning, and (2) the teacher had been judged by peers, instructional supervisors, and administrators to be competent and skillful in instructional techniques.

The five teachers included in the study were trainers of other teachers in the skills of instruction. They ranged in years of experience from six to 21 years. None of the project teachers were members of the fifth-grade staff, and all of the teachers were female. It is important to note 
that though only five teachers are required in the design for the study, six teachers were actually selected. The sixth teacher was included and trained so that there would be a back-up teacher in the event that one of the other five teachers became ill or incapacitated. All six teachers helped in the lesson planning phase, the field study, and in observing for bias. All teachers were involved in helping to plan the lesson, the posttest, and the criteria for judging bias in the lesson.

Each beacher was assignea to teach the active participation lesson twice and the non-active participation lessor twice. Within each method (level of treatment), classes were assigned randomly to teachers; therefore, each teacher was assigned to teach four lessons in total with two lessons each in both lesson treatments. The results of the random assignment of classes to level of treatment and of the random assignment of classes within level to teachers is illustrated in Table I.

\section{Training Procedures}

Since the treatment consisted of one 30-minute lesson modified to reflect the two levels of the independent variable, it was important that the lesson be thoroughly planned and that the lesson be taught consistently. Initially, the teachers in this study were selected for their teaching expertise and for their knowledge of Hunter's elements of 
TABLE I

RANDOM ASSIGNMENT OF CLASSES TO TEACHERS AND METHOD

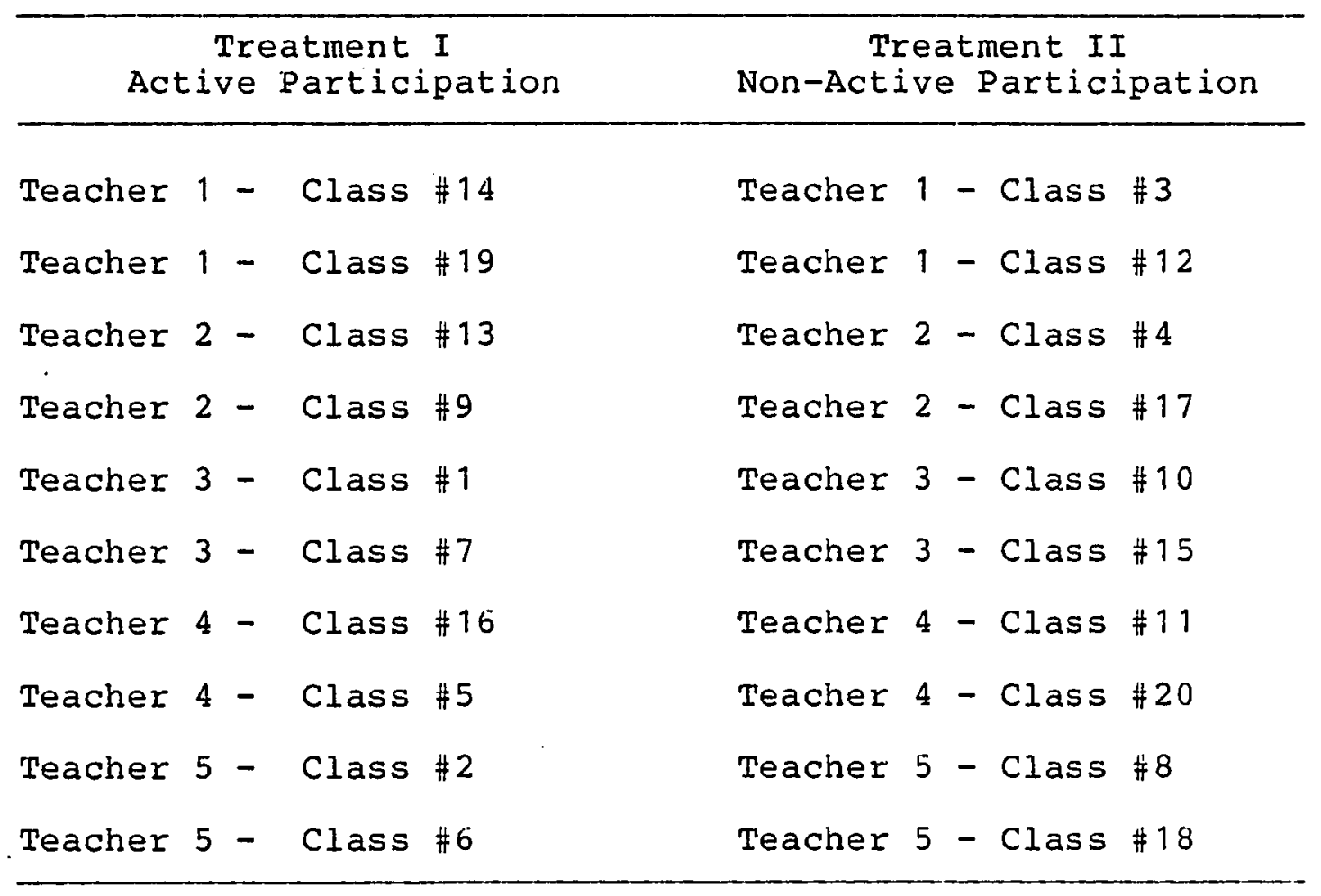


instruction. Training in specific techniques was an important criterion for project teacher selection, on the assumption that teachers with similar training would more likely teach similarly and teachers trained in the use of the principles of learning are more apt to be conscious of whether or not they are employing or excluding a specific method such as active participation.

The first task of the project teachers was to know and understand the project. An initial orientation meeting was conducted in which the study was explained in depth and the activities of the participating teachers were identified. In this meeting, the confidentiality of the study was stressed to insure neither the students in the project nor their regular classroom teachers knew the nature of the lesson or method.

The next step was to plan the lesson. Ultimately the lesson topic, objectives, and the task analysis would be selected by the investigator. However, it was imperative to have all of the project teachers involved in planning the lesson to insure a more thorough understanding of the intent and design of the lesson as well as to utilize the expertise of a number of professionals in this activity. During the lesson planning phase, ideas and activities were tested and challenged on the basis of effectiveness and relevancy to the lesson. Also, in addition to the theoretical definition of active participation, a working definition of active 
participation was developed and clarified. The two teaching modes were alike in every respect except that of active participation. An exact transcript is found in Appendix A. The next task of the six project teachers, investigator, curriculum specialist, and staff development specialist was to develop an appropriate posttest for the lesson. The important objective for training was that the project teachers understand the one-to-one relationship between objectives offered in the lesson and items offered on the posttest. This relationship is illustrated in Table II. The fourth training session of the project teachers consisted of practicing the lesson. Each teacher had an opportunity to actually teach the lesson to her peer project teachers. Then each teacher was critiqued on the basis of lesson content, pacing, time expiration, bias, and of course the use or non-use of active participation. This process not only afforded teachers practice and feedback but also served as a model to the other project teachers. During this session, criteria for bias in the lesson and elements of consistency were developed. For example, it was important that all of the lessons be of equal time. Therefore, this factor was considered in evaluating the consistency between lessons. The resulting criteria were used by the investigator and the staff development specialist in reviewing video- and audio-tapes for bias and consistency. 
TABLE II

TABLE OF SPECIFICATIONS FOR THE

CRITERION POSTIEST

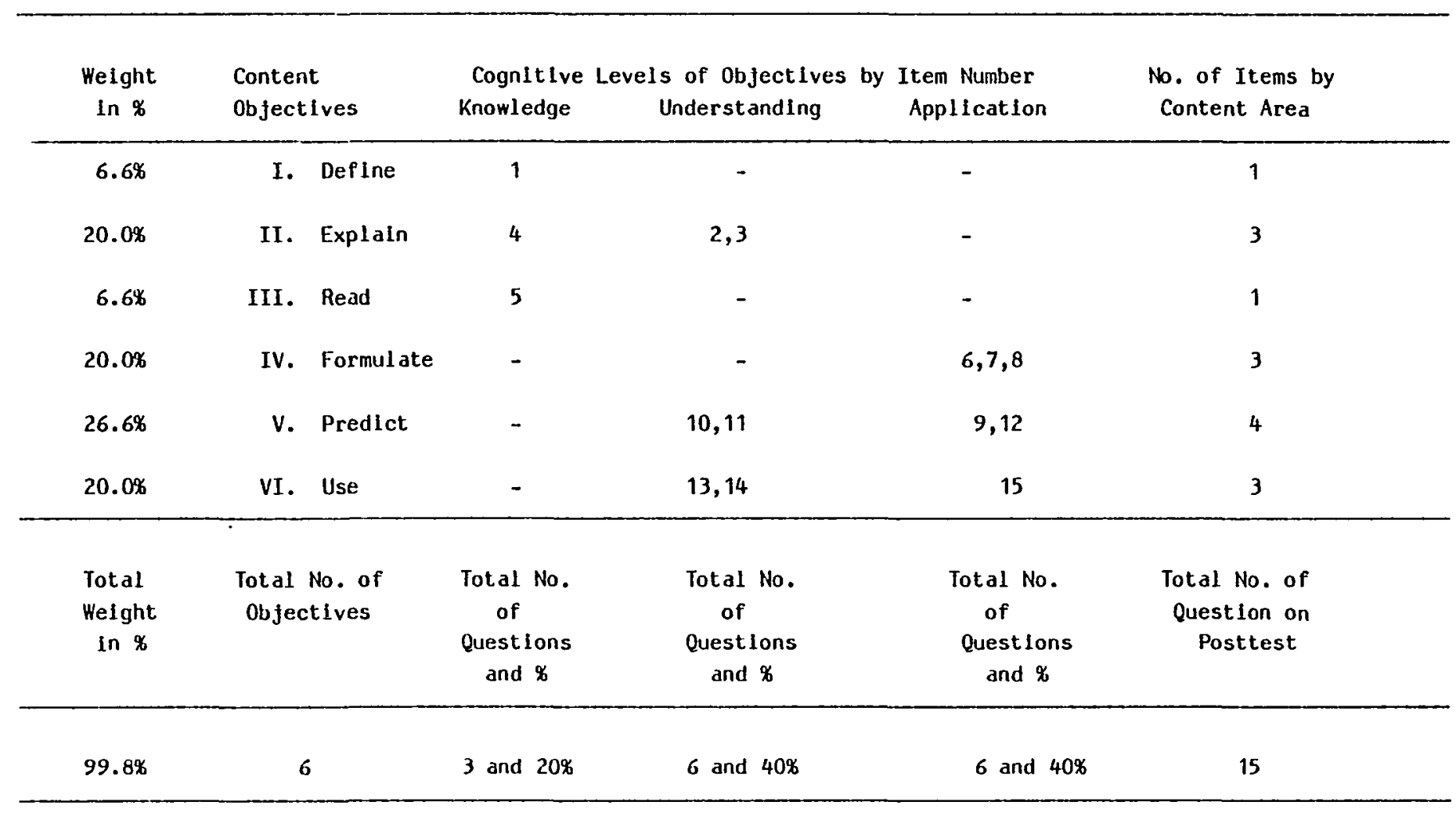


After the fourth session, the teachers were ready to field test the lesson and the posttest. The purpose for the field test were: A) to give the teachers practice with a class of students in a real setting, B) to test the validity and practicality of the lesson, C) to check the posttest for sensitivity to change, and D) to give the team of project teachers one final opportunity to monitor, critique, and adjust their teaching and/or the lesson. The field test gave each teacher an opportunity to teach the lesson once with each treatment level (or a total of two times). At the end of the field test, the teachers again received feedback on their performance in terms of lesson content and consistency by reviewing the video- and audio-tapes with the investigator.

In addition to the project teachers, other personnel had to be taken into account. The principals' support and understanding were essential for a positive climate among both classroom teachers and students. Therefore, two planning sessions with all principals together were conducted, in addition to the initial telephone contact, to clarify and schedule the instruction time.

Other essential persons taken into consideration were the classroom teachers. They were notified and informed about the project in general, but not in specifics. The classroom teachers needed to know how to prepare the class without biasing the lesson or creating a negative feeling 
towards the project teachers. Therefore, a meeting of all classroom teachers together was planned and executed to explain the researcher's expectations for the classroom teacher and the scheduling.

Information was given to the students prior to the lesson by the classroom teacher and a brief explanation was given by the project teacher at the beginning of each lesson. Essentially, the student needed to be aware that cooperation was necessary, that the teacher supports the activity, and that the project teachers were working to improve instruction.

Instrumentation

Three instruments were developed and field tested for this study: (1) the iesson plan, (2) the postest, and (3) the criterion checklist for bias and consistency among the 20 presentations of the lesson.

\section{The Lesson}

The lesson was designed by the investigator in consultation with the fifth-grade project teachers, the elementary school principals of the district, and the district's curriculum and staff development specialists. The development of the lesson to be presented involved four stages: selection of a topic, (2) identification of lesson objectives, (3) construction of a lesson plan, and (4) the modification of the lesson plan to reflect the two levels of 
treatment. Three criteria were used in the selection of the topic: the topic must not be in the fifth-grade curriculum, it must be a topic that fifth-grade students are unlikely to have encountered before, and it must be possible to adequately cover the topic in a 30-minute lesson. Simple probability was selected as the topic because it was considered to meet these criteria. A set of objectives for the lesson was then identified and evaluated using appropriate difficulty, time limits imposed on the lesson, balance between abstract concepts and concrete application, and potential for posttest measurement as criteria. A copy of the lesson outline is presented in Appendix A.

The next task was to apply the two treatment levels to the lesson in such a manner that the lesson content and objectives were not significantly changed (except in terms of the independent variable) and the time required to teach the lesson was unaltered. Since a teacher who uses active participation is likely to use more time than a teacher who does not, the team built into the lesson an alternate to active participation that would both be instructionally sound and be of equivlent time. This was done using teacher talk (lecture), teacher demonstration, and modeling. The critical aspect of the lesson development was to design everything the same in both lessons with the exception of active participation. One lesson must have no active 
participation; and the other lesson must have it, but only as it actually might be used in typical classroom settings.

\section{The Posttest}

Once the lesson was constructed, the next task was to design a posttest (dependent variable criterion test) that accurately measured the students' understanding of the lesson objectives. It was essential not to include anything that had not been taught in the lesson and only inciude test items that had a direct relationship to the objectives of the lesson. Since the lesson had several specific subobjectives of the main topic, simple probability, several test questions for each objective were designed. The posttest was designed to include the six lesson objectives at three cognitive levels: (1) knowledge, (2) understanding, and (3) application. Three questions dealt with knowledge, six questions with understanding, and six with application. The test specifications illustrating the objectives and cognitive emphasis is illustrated in Table II (p. 48). Another consideration in developing the posttest was test format. The multiple choice design was selected due mainly to its objective scoring. Using objective scoring with one correct answer would eliminate any subjective assessinent during test scoring. The reliability of the posttest was .59 by the Kuder-Richardson 21 method of 
estimation. Although a higher coefficient was hoped for, the decision to proceed was maae on the belief that no serious threat to research valiaity was present. A copy of the posttest is found in Appendix B.

\section{Teaching Consistency}

The last instrument developed for the study was for assessing teaching consistency. With five teachers involved in 20 classrooms with approximately 500 students in different schools using different treatments, it was decided to video-tape or audio-tape each lesson so that it could be reviewed at a later time for bias and compared with other lessons for similarity and consistency. Consequently, the specialists reviewing the lessons needed specific criteria on which to base their observations and comments. Therefore, the investigator, assisted by the team of project teachers and curriculum and staff development specialists, identified 30 specific elements to be considered in assessing the consistency in teaching the lesson. The project teachers were involved in this planning phase so that they would be keenly aware of pitfalls to be avoided prior to their teaching the lesson. A copy of the criterion sheet that was used to evaluate each lesson may be located in Appendix $\mathrm{C}$.

\section{Field Testing}

The lesson, the posttest, and the criteria checklist were all field tested prior to their use with the fifth- 
grade students. Each of the project teachers taught the lesson and administered the posttest to two classes, for a total of ten classes taught. Each teacher taught one lesson with active participation and one lesson without it. The data gathered were used to make final adjustments in the lesson, the posttest, and the criteria checklist. The field test; in addition to monitoring and adjusting the procedures and instruments, also gave the teachers an opportunity to practice with a class of students. This was important for maintaining as much consistency as possible. And finally, the field test provided an opportunity to check the posttest for adequacy.

\section{Data Gathering Procedures}

Since consistency was deemed important in this study, measures were taken to insure similar conditions. All lessons were taught in the morning between 9:00 and $11: 00$ in the students' normal homeroom setting. Prior to the project teacher's arrival, the homeroom teacher, acting upon specific instructions from the investigator, prepared the class for the project lesson. In addition, video equipment was set up by school personnel prior to the teaching of the lesson but was not brought into the classroom until the arrivai of the project teacher. The homeroom teacher then introduced the project teacher to the students. The project teacher 
proceeded to inform the class about her purpose for teaching the lesson and how the lesson and posttest would proceea. This took approximately five to ten minutes in most cases. Students were aware that they were a part of a project lesson which would provide information for improvement of instruction. The operation of the video equipment during the lesson was performed by school personnel.

The project teacher then instructed the students using the project lesson plan which was followed step by step. When the instruction was completed, information was given to the students about the posttest. The students were given directions on how to take the test, sample questions were marked, and then the students were allowed as much time as they needed to complete the test. The student tests were then placed in a marked folder and sent to the test scorer. All lessons were both video- and audio-taped, and the completed tapes were forwarded to the investigator. Both video- and audio-taping were done to insure against a possible malfunction in the equipment. Since some video-tapes were unintelligible, it as fortunate that the practice of dual taping was followed.

All teachers recorded the minutes elapsed during the teaching of the lesson, the number of students involved, the time of day, and the unusual events or interruptions that may have occurred. 
The amount of time spent on the lesson by the teacher was an important consideration. Bloom (1976), in his theory of mastery learning, clearly indicates that all things being equal the student spending more time on a lesson will learn content objectives more thoroughly. Therefore, it was important that time be similar for all lessons taught. Using the bias checklist, the video- and audio-tapes were reviewed by the investigator, the staff development specialists, and a curriculum specialist. This information together with information provided by the project teachers comprised the total information included in the bais survey. In completing the bias checklist form, the person reviewing the tape tallied instances of interruptions and answered the yes or no questions on the checklist. The bias surveys were then forwarded to the investigator, and bias data were compiled for all lessons. Since all of the bias surveys were identical in results, the bias survey was judged to possess high reliability.

Data Analysis Procedures

Two types of data were analyzed. The first, directly relevant to the research hypothesis, were the scores from the dependent variable criterion test of the students who participated in the study. Tables showing the means, standard deviations, variances, and frequency distributions of the ten classes within each treatment were constructed to 
provide a visual display of data. Using the class means as units of data, the mean, standard deviation, and variance of the class means were calculated for each treatment level and displayed in a table. The statistical hypothesis was tested using an independent t-test.

The video- and audio-taped lessons, together with the observation checklist for bias, provided a second source of data. The tapes were reviewed by two staff development specialists, a curriculum specialist, two project teachers, and the researcher. The data on the survey forms were analyzed and expressed tabularly for each treatment level. Length of lesson and number of students present on the day of the lesson were considered to be of sufficient importance to justify further analysis. The length of lesson for each class within each treatment level was calculated and presented in a table. An independent t-test was calculated testing the statistical hypothesis that the mean lengths of lesson for subjects in the two treatment levels were equal. The relation between class size (number of students present at time of treatment) and achievement was investigated for each treatment level separately using spearman's rho. The statistical hypothesis of no relation was tested at the .05 level. 


\section{CHAPTER IV}

\section{PRESENTATION AND ANALYSIS OF DATA}

As discussed in Chapter II, the assumption upon which this study is based is that the teacher by his or her actions can make a difference in how well students learn. The intent of this dissertation was to contribute to existing research on the effects of teaching on learning. Specifically, the study investigated whether or not the method of active participation employed by a teacher has an effect on learning. The research expectation was that children taught with active participation will achieve more than children taught without active participation.

\section{Sample}

The 20 fifth-grade homeroom classes of a suburban northwest, medium-sized school district comprised the sample, with classes being randomly assigned to treatment level and, within each treatment level, teachers. Each teacher taught two lessons under each method. A total of 213 students were present and participated in the study on the days in which the 10 clases of "Active Participation" (Treatment I) were taught. For the 10 "Non-Active 
Participation" classes (Treatment II), a total of 234 students received instruction and completed the posttest.

Presentation and Tabulation of Data by Class

The frequency distribution, mean, standard deviation, variance and class size for each class within each treatment are presented in Tables III and IV. The following may be discovered by a comparison of the two tables.

1. The average class-size of classes in Treatment I was 21.30 students whereas the average class-size for Treatment II was 23.40. Therefore, the classes receiving Treatment II tended to be slightly larger.

2. There were more individual student scores below the score of eight in Treatment II (25 scores) than in Treatment I ( 2 scores).

3. The posttest class means for Treatment I ranged from 11.761905 to 13.083333 , whereas the class means for Treatment II ranged from 10.692308 to 11.545455. In all cases, the class means are higher in Treatment I than they are for Treatment II.

4. The standard deviations were somewhat similar within each treatment, but slightly larger for treatment II than for treatment I. This lends 
TABLE III

MEANS, STANDARD DEVIATIONS, VARIANCES, AND FREQUENCY DISTRIBUTIONS

OF SCORES BY CLASS WITHIN TREATMENT I

\begin{tabular}{|c|c|c|c|c|c|c|c|c|c|c|c|}
\hline & & & & Classe & and Number & f Correct I & ems on the & osttest & & & \\
\hline \multicolumn{12}{|c|}{ Post-test } \\
\hline Scores & 1 & 2 & 3 & 4 & 5 & 6 & 7 & 8 & 9 & 10 & Total \\
\hline 15 & 2 & 2 & 5 & 0 & 2 & 1 & 4 & 3 & 5 & 1 & 25 \\
\hline 14 & 4 & 3 & 4 & 6 & 5 & 9 & 7 & 9 & 2 & 7 & 56 \\
\hline 13 & 7 & 3 & 3 & 3 & 1 & 4 & 5 & 3 & 4 & 5 & 38 \\
\hline 12 & 3 & 4 & 3 & 3 & 5 & 0 & 6 & 6 & 3 & 3 & 36 \\
\hline 11 & 2 & 2 & 2 & 0 & 1 & 2 & 3 & 2 & 2 & 1 & 17 \\
\hline 10 & 2 & 4 & 2 & 2 & 2 & 2 & 2 & 1 & 4 & 3 & 24 \\
\hline 9 & 2 & 2 & 2 & & 1 & 2 & & & 2 & 1 & $1 ?$ \\
\hline 8 & & 1 & & & & & & & 1 & 1 & 3 \\
\hline 7 & & & & & & & & & & 1 & 1 \\
\hline 6 & & & & & & & & & & 0 & 0 \\
\hline 5 & & & & & & & & & & 1 & 1 \\
\hline \multicolumn{12}{|l|}{4} \\
\hline \multicolumn{12}{|l|}{3} \\
\hline \multicolumn{12}{|l|}{2} \\
\hline \multicolumn{12}{|l|}{1} \\
\hline \multicolumn{12}{|l|}{0} \\
\hline N & 22 & 21 & 21 & 14 & 17 & 20 & 27 & 24 & 23 & 26 & 213 \\
\hline $\bar{x}$ & 12.409091 & 11.761905 & 12.666667 & 12.785714 & 12.529412 & 12.650000 & 12.888889 & 13.083333 & 12.130435 & 11.833333 & \\
\hline$S$ & 1.723081 & 1.886631 & 1.874064 & 1.371098 & 1.751901 & 1.851351 & 1.474056 & 1.351440 & 2.173043 & 2.527625 & \\
\hline$s^{2}$ & 2.969008 & 3.990930 & 3.836508 & 1.882653 & 3.072664 & 3.427500 & 2.172840 & 1.826389 & 4.722117 & 6.388889 & \\
\hline
\end{tabular}


TABLE IV

MEANS, STANDARD DEVIATIONS, VARIANCES, AND FREQUENCY DISTRIBUTIONS OF SCORES BY CLASS WITHIN TREATMENT II

\begin{tabular}{|c|c|c|c|c|c|c|c|c|c|c|c|}
\hline & & & & Classe & and Number & f Correct I & ems on the & osttest & & & \\
\hline \multicolumn{12}{|c|}{ Post-test } \\
\hline Scores & 1 & $?$ & 3 & 4 & 5 & 6 & 7 & 8 & 9 & 10 & Total \\
\hline 15 & 1 & 1 & 2 & 2 & 1 & 2 & 2 & 2 & 2 & 1 & 16 \\
\hline 14 & 6 & 1 & 3 & 3 & 1 & 4 & 3 & 3 & 2 & 2 & 28 \\
\hline 13 & 3 & 5 & 5 & 5 & 6 & 5 & 3 & 3 & 4 & 4 & 43 \\
\hline 12 & 3 & 3 & 5 & 1 & 1 & 2 & 2 & 6 & 4 & 7 & 34 \\
\hline 11 & 3 & 4 & 2 & 2 & 3 & 6 & 0 & 4 & 6 & 0 & 30 \\
\hline 10 & 1 & 1 & 3 & 3 & 4 & 4 & 5 & 0 & 2 & 6 & 29 \\
\hline 9 & 2 & 2 & 2 & 0 & 2 & 2 & 2 & 2 & 1 & 4 & 19 \\
\hline 8 & 1 & 0 & 0 & 1. & 1 & 0 & 4 & 2 & 0 & 2 & 11 \\
\hline 7 & 2 & 0 & 1 & 1 & 1 & 1 & 0 & 1 & 0 & 0 & 7 \\
\hline 6 & 2 & 0 & 1 & 3 & & 0 & 0 & 0 & 0 & 1 & 7 \\
\hline 5 & 1 & 0 & 2 & & & 0 & 1 & 1 & 0 & & 5 \\
\hline 4 & 1 & 0 & & & & 1 & & 1 & 0 & & 3 \\
\hline 3 & & 0 & & & & & & & 0 & & 0 \\
\hline 2 & & 1 & & & & & & & 0 & & 1 \\
\hline 1 & & & & & & & & & 1 & & 1 \\
\hline \multicolumn{12}{|l|}{0} \\
\hline $\mathbf{N}$ & 26 & 13 & 27 & 21 & 20 & 27 & 22 & 25 & 22 & 27 & 234 \\
\hline $\bar{x}$ & 10.692308 & 11.333333 & 11.153846 & 11.142857 & 11.250000 & 11.481481 & 10.909091 & 11.080000 & 11.545455 & 11.000000 & \\
\hline $\mathbf{s}$ & 3.207794 & $2.7+8737$ & 2.824240 & 2.948538 & 2.070628 & 2.439951 & 2.678349 & 2.855451 & 2.775334 & 2.125681 & \\
\hline $\mathrm{s}^{2}$ & 10.289941 & 7.555556 & 7.976331 & 8.693878 & 4.287500 & 5.953361 & 7.173554 & 8.153600 & 7.702479 & 4.518519 & \\
\hline
\end{tabular}


support to the contention that the classes that participated in the study tended to be homogenous.

5. The distributions tended to be skewed left, more so for Treatment I than for Treatment II.

\section{Comparison of Treatment Levels}

Using the classes as the unit for analysis, means, standard deviations, variances and sample size were calculated and are presented in Table $V$. The mean of the class means for the "Active Participation" classes was 12.469484, whereas the mean of the class means for the "NonActive Participation" classes was 11.149573 The variances for Treatment I and Treatment II were 0.175154 and 0.06415 , respectively.

The study was designed to compare the mean of class . means in Treatment I with the mean of class means in Treatment II, using an independent $t$-test. The results of this analysis are presented in Table $V$. Using a two-tailed test, with alpha set at .05 and 18 degrees of freedom, the critical-t was 2.101 (Glass and Staniey, 1970, p. 521). The calculated-t was 8.128282 . Since the calculated-t $(8.127137)$ was greater than the critical-t $(2.101000)$, the statistical hypothesis was rejected at the .05 level of significance. 
TABLE V

MEANS, STANDARD DEVIATION, VARIANCE, DEGREES OF FREEDOM AND STUDENT T-TEST BETWEEN TREATMENT

GROUPS I AND II

\begin{tabular}{|c|c|c|}
\hline & $\begin{array}{l}\text { Treatment I } \\
\text { (Active Participation) }\end{array}$ & $\begin{array}{l}\text { Treatment II } \\
\text { (Non-Active Participation) }\end{array}$ \\
\hline $\mathrm{N}$ & 10 & 10 \\
\hline $\bar{x}$ & 12.4694840 & 11.149573 \\
\hline S & 0.418514 & 0.245796 \\
\hline \multirow[t]{5}{*}{$s^{2}$} & 0.175154 & 0.060415 \\
\hline & degrees of Ereedom & $=18$ \\
\hline & Alpha (two-tailed) & .05 \\
\hline & calculated-t & $=+8.128282^{*}$ \\
\hline & critical-t & $=+2.101000$ \\
\hline
\end{tabular}

*Significant beyonà .001 level 
The statistical hypothesis $\left(\mathrm{H}_{0}: \mu_{1}=\mu_{2}\right)$ that there is no difference between the mean of classes taught with active participation and the mean of the classes taught without active participation was rejected, as was the alternative hypothesis $\left(H_{2} M_{1}<\mu_{2}\right)$. The research hypothesis $\left(\mathrm{H}_{1}: \mu_{1}>\mu_{2}\right)$ that the mean of the classes taught with active participation is greater than the mean of the classes taught without active participation was accepted.

Analysis of Lesson Presentation

The data collected was examined in several ways for possible contamination, bias, and threats to validity. While reviewing the video- and audio-tapes for bias, the survey criteria forms were examined for consistency. The bias survey included tallied data, external factors, student factors, and teacher factors with 30 rated items. The results of an analysis of this data is presented in Table VI. The check for bias did not uncover any inconsistencies in instruction, classrooms, groups of students, or external factors. For example, praise used in Treatment I averaged 14.700000 and Treatment II 14.900000 times. Student disruptions averaged .800000 times in Treatment $I$ and .300000 times in Treatment II. Also, the number of times active particpation was used was consistent between teachers. The mean for the uses of active participation in all lessons was 
TABLE VI

OBSERVATION RESULTS OF BIAS CRITERIA SURVEY (NUMBER OF INCIDENTS)

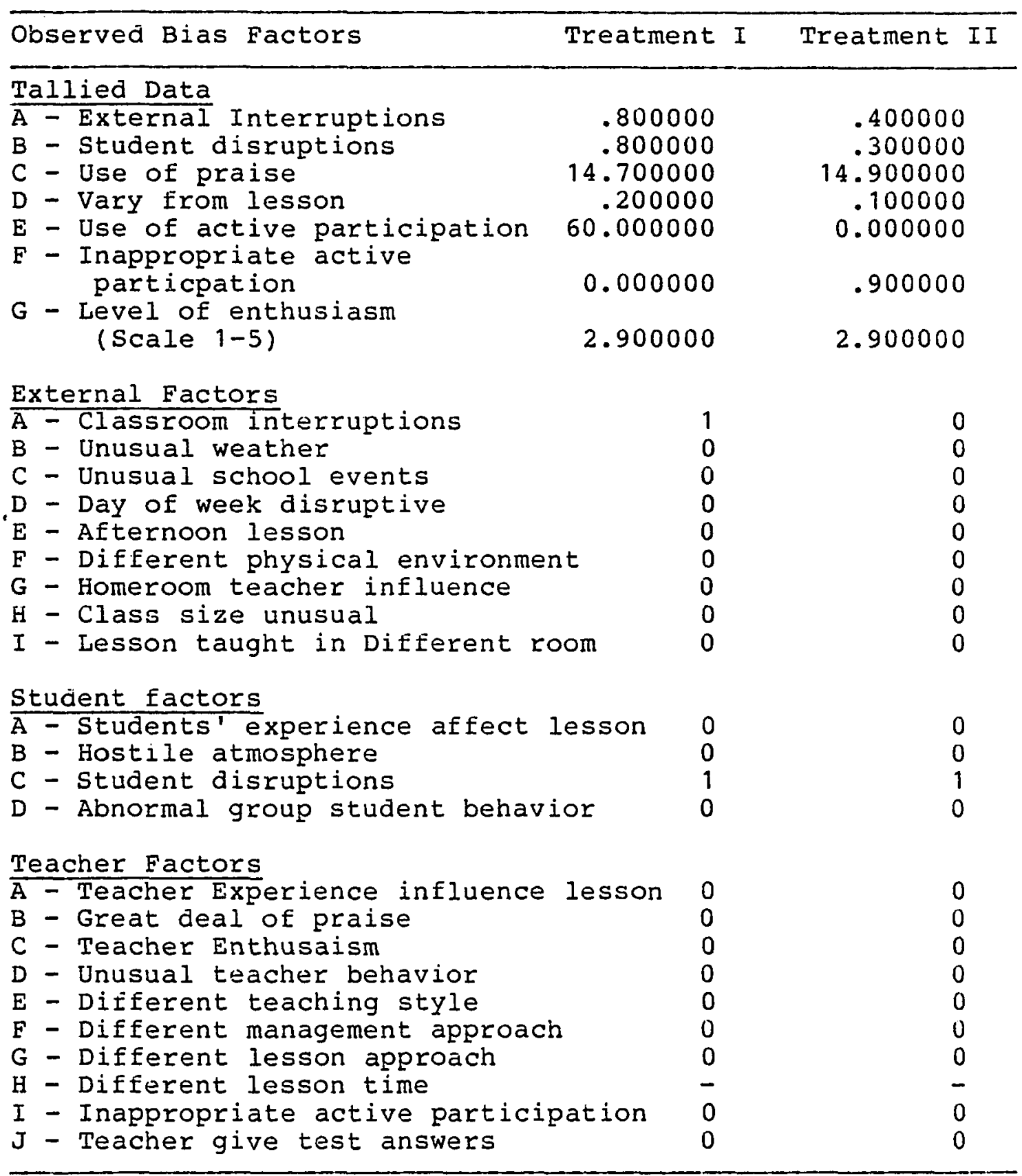


60 times. The only noticeable aifference was between teacher styles. Some teachers appeared to be more businesslike while others appeared more casual, smiling, and frienaly. However, each teacher remained consistent to her style of delivery in all four lessons she taught. It was concluded that differences between bias in lessons between Treatments I and II were not significant. There were two influencing factors out of 220 possibilities in Treatment $I$ and two influencing factors out of 220 possibilities in Treatment II. A comparison of bias results can be found in Table VI.

\section{Comparison of Lesson Time}

Another factor for concern in consistency was duration of the lesson. If the time of lessons in lreatment I was longer than the time of lessons in Treatment II, it could be argued that the lesson duration may account for some ajifferences that might appear. Consequently, the time for each lesson was recorded by each project teacher and double checked when the video- and audio-tapes were reviewed for bias. A t-test was calculated on the tabulated times for lesson duration for each class within each method. The results appear in Tables VII and VIII.

The mean lesson time for Treatment I was 29.6, whereas the mean lesson time for Treatment II was 29.1 minutes. Al- 
TABLE VII

TIME DURATION FOR PROJECT LESSONS

\begin{tabular}{|c|c|c|c|c|c|}
\hline \multicolumn{3}{|c|}{$\begin{array}{c}\text { Treatment I } \\
\text { (Active Participation) }\end{array}$} & \multicolumn{3}{|c|}{$\begin{array}{c}\text { Treatment II } \\
\text { (Non-Active Participation) }\end{array}$} \\
\hline Class & $\# 14$ & $26 \mathrm{~min}$. & Class & $\# 3$ & $27 \mathrm{~min}$. \\
\hline Class & $\# 19$ & $28 \mathrm{~min}$. & Class & $\# 12$ & $28 \mathrm{~min}$ \\
\hline Class & $\# 13$ & $30 \mathrm{~min}$. & Class & $\# 4$ & $30 \mathrm{~min}$ \\
\hline Class & $\# 9$ & $31 \mathrm{~min}$. & Class & \# 17 & $29 \mathrm{~min}$ \\
\hline Class & $\# 1$ & $24 \mathrm{~min}$. & Class & $\# 10$ & 25 min. \\
\hline Class & $\# 7$ & $27 \mathrm{~min}$. & Class & $\# 15$ & $29 \mathrm{~min}$. \\
\hline Class & $\# 16$ & $35 \mathrm{~min}$. & Class & \#11 & $35 \mathrm{~min}$. \\
\hline Class & $\# 5$ & $35 \mathrm{~min}$. & Class & $\# 20$ & $35 \mathrm{~min}$. \\
\hline Class & $\# 2$ & $30 \mathrm{~min}$. & Class & $\# 8$ & $26 \mathrm{~min}$. \\
\hline Class & \# 6 & $30 \mathrm{~min}$. & Class & $\# 18$ & $27 \mathrm{~min}$. \\
\hline $\begin{array}{l}\text { Mean of } \\
\text { Classes }\end{array}$ & 29. & $000 \mathrm{~min}$. & $\begin{array}{l}\text { Mean } \\
\text { Classe }\end{array}$ & & $29.100000 \mathrm{~min}$. \\
\hline
\end{tabular}




\section{TABLE VIII}
MEANS, S'TANDARD DEVIATION, VARIANCE, AND STUDENT T-TEST FOR TIME, IN MINUTES OF PROJECT LESSOINS

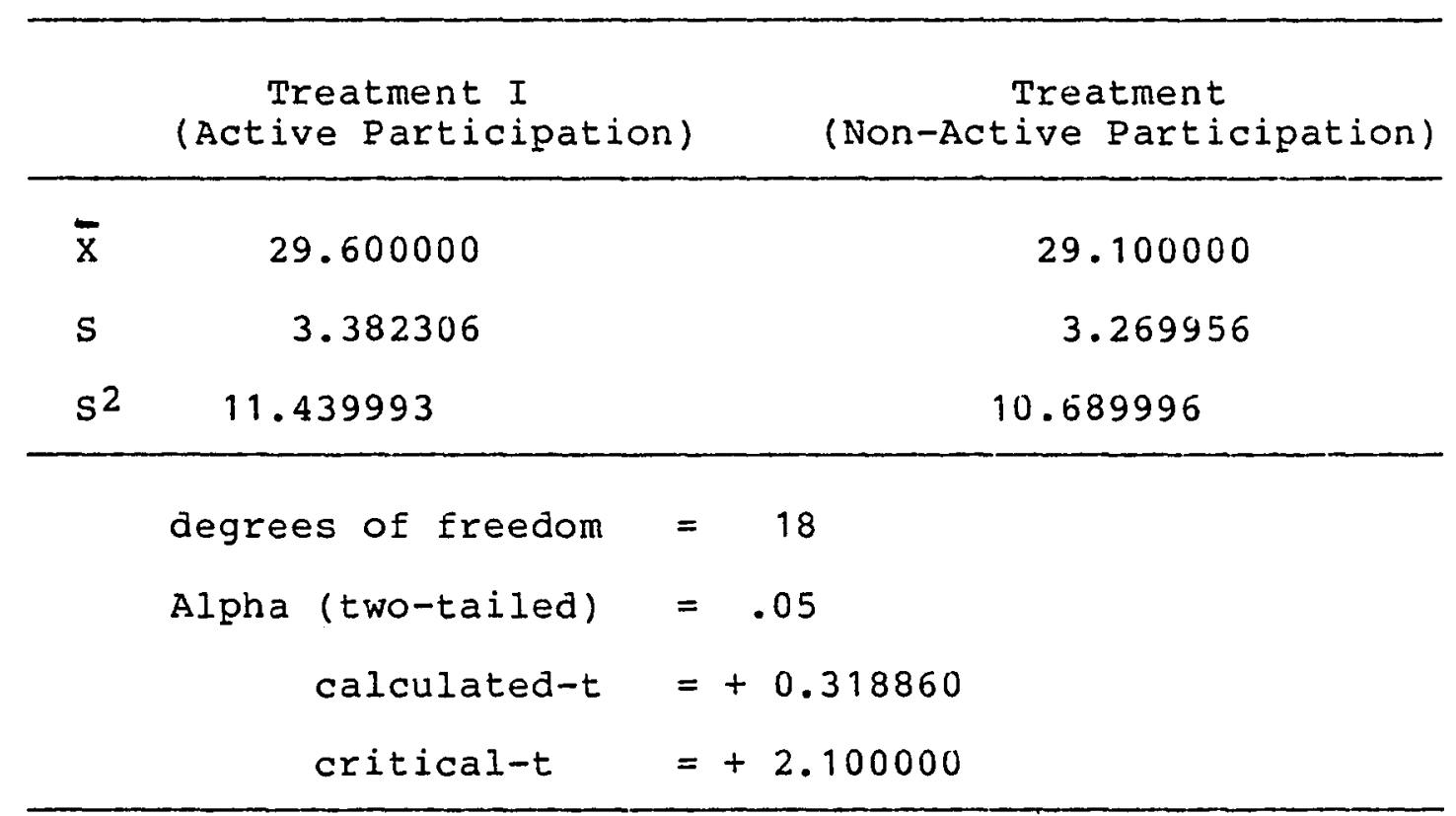


though there appears to be some numerical difference between the time means of the two samples, it is important to note two points. First, the statistical hypothesis that the mean lesson time for classes taught by Active Participation is equal to the mean lesson time of classes taught by Nonactive Participation $\left(\mathrm{H}_{\mathrm{O}}: \mu_{1}=\mu_{2}\right)$ was not rejected. (Calculated-t $=+0.318860 ;$ critical-t $= \pm 2.101000$, for alpha $=.05$ and 18 degrees of freedom.) Second, each project teacher remained fairly consistent in the amount of time it took to teach each of four lessons within the two. treatments. For example, one project teacher taught classes one and two in both treatments, and the difference in the longest and shortest time duration for that teacher was two minutes. Although some project teachers, spent more time on their lessons than did other project teachers, the time spent within a specific project teacher's lessons remained reasonably consistent from one to the next.

\section{Comparison of Class Characteristics}

The class size and the number of students present for participation in the study are shown in Table Ix for each class within each treatment. Although classes were randomly assigned to treatment, a difference between the two levels was found, with the non-active particpation group having slightly larger classes. The average class size for Treatment I was 24.9 and for Treatment II was 25.2 , a non-signi- 
TABLE IX

CLASS ENROLLMENT AND CLASS ATTENDANCE FOR ACTIVE PARTICIPATION AND NON-ACTIVE

PARTICIPATION GROUPS

\begin{tabular}{cccccc}
\hline Active & Participation & \multicolumn{2}{c}{ Non-Active Participation } \\
\hline Class & $\begin{array}{c}\text { Class } \\
\text { Enroll. }\end{array}$ & $\begin{array}{c}\text { Class } \\
\text { Attend. }\end{array}$ & Class & $\begin{array}{c}\text { Class } \\
\text { Enroll. }\end{array}$ & $\begin{array}{c}\text { Class } \\
\text { Attend. }\end{array}$ \\
\hline 14 & 25 & 22 & 3 & 26 & 26 \\
19 & 26 & 21 & 12 & 22 & 18 \\
13 & 24 & 21 & 3 & 27 & 27 \\
9 & 21 & 14 & 17 & 25 & 21 \\
1 & 23 & 17 & 10 & 23 & 20 \\
7 & 24 & 20 & 15 & 28 & 27 \\
16 & 29 & 27 & 11 & 24 & 22 \\
5 & 24 & 24 & 20 & 26 & 25 \\
2 & 25 & 23 & 8 & 23 & 22 \\
6 & 28 & 26 & 18 & 28 & 27 \\
\hline Mean & 24.9 & 21.5 & Mean & 25.2 & 23.5 \\
\hline
\end{tabular}


ficant difference. When the number of participating students is considered, the difference between treatment groups increases with the non-active particpating group having the larger class attendance on the average. The average class attendance on the day of the lesson was 21.5 for Treatment Group I and 23.5 for Treatment Group II. As calculated by a $t$-test the difference was found to be non-significant.

Research concerning the relationship between achievement and class size suggests that class size is not. an important variable except for very small classes. This was described by Educational Research Service in a recent Phi Delta Kappan article (Glass and Smith; December, 1980; page 239). Nevertheless, because of its potential influence, the relation betwen class size and achievement was examined as it impacts this study. To control for the treatment effect in examining the relation between class size and achievement, a spearman rank order coefficient of correlation was calculated for each treatment group. The ten classes within each group were ranked two times: on the basis of number of participants in the study, and on the basis of mean achievement. To correct for ties, a Pearson's coefficient of correlation was calculated on the ranks. For each group separately, the statistical hypothesis that the population coefficient is zero was tested at the .05 level, using a procedure described by Glass and stanley (1970, page 316). 
The critical value of rho for both tests was +.648 . The correlation between class attendance and achievement for Treatment Group I was + .033 and for Treatment Group II was -.209. Both statistical hypotheses were retained. 
CHAPTER $V$

CONCLUSIONS AND RECOMMENDATIONS

This study proposed to provide an answer to whether or not the method of active particpation employed by a teacher can significantly enhance student learning as measured by an immediate posttest. The implications of the findings will be discussed in six parts: 1) Research Outcomes, 2) The Research Design, 3) Limitations, 4) Implications for the Classroom, 5) Implications for Research, 6) Recommendations, and 7) A Summary Statement.

\section{Research Outcomes}

Since the research hypothesis was accepted, this investigation confirms that the treatment variable, active participation, does make a difference in the degree of student learning as measured by an immediate posttest. Though the previous statement is perhaps obvious, its implications are many and varied. Probably the most important conclusion to be set forth is the notion that the teachers can have positive effects on the learning of their students.

What further should be said about the use of active participation in the classroom? First, it is an efficient 
teaching method. What this means for the teacher and the student is that subjects can be learned well over short perioas of time. Though one could argue that the difference in Iearning between active participation and non-active participation was shown to be quite small for one lesson over a short perod of time, the accumulative effects of small portions of incremental learning over long periods of time could very well make an appreciable difference in the total learning of a student as well as leaving more time for the teacher to address other matters.

Active participation was found to be effective in normal, typical classroom settings with classroom teachers. As Brophy $(1979 b)$ pointed out, research conducted in typical classroom settings is more likely to generate resuits that will be used by teachers and results that will actually work. Brophy further argued that even though research in these settings is sometimes less rigorous, it is still important to use the intact group. Replications should then attempt to verify the findings. This is an important notion because educators want methods that have been proven to work in classrooms. Most teachers tend to avoid the theoretical and are attracted to the more practical examples and proceäures.

Another benefit of active participation relates to time on task. Active participation forces the teacher and 
student in the learning process to spend proportionally more time and activity doing something which requires thinking, responding, and verifying what the learner does or does not know. Therefore, immediate adjustments can be made by the teacher for the students' benefit. Bloom (1976) and Doyle (1979) both support the practice of time on task as an effective means to learning. Simply stated, active participation is a vehicle that creates a situation conducive to time on task.

A word of caution is appropriate. This study was done with a planned lesson that was taught by competent and highly trained teachers using the theoretical methods advocated by Hunter (1976). Active participation was one component among many that contributed to a successful lesson. Active participation alone will not create an environment for successful iearning. However, when it works in harmony with appropriate objectives selected at the correct level of difticulty and is taught by a skiliful teacher who knows what methods to apply, it will reach its fullest potential as a method for enhancing learning.

This study has helped to move active participation from the strictly theoretical to the realm of the empirical. Though further study is required, the concept of active participation has at least to some degree been proven effective. In Teachers Make a Difference, Good, Biddle, and Brophy (1975) draw what seems to be an appropriate con- 
clusion for this study when they say "some teaching methods are more effective than others, even when the curriculum is identical" (page 67). This study demonstrates that one of those methods is active participation.

The Research Design

As in most research projects, there were aspects of the study that went as expected or even exceeded some expectations; and there were features of the study that could be improved upon. First, the aspects perceived as strengths will be discussed, and then the aspects perceived as shortcomings will be discussed.

One of the initial strengths of this study was the project teachers. They are all teachers who were well trained in their profession. Their universal key characteristics that benefited this study was their ability to know which behaviors on their part would elicit certain behaviors on the part of their students. In other words, their teaching was deliberate and proactive rather than intuitive and reactive. They all knew when they were using active participation or not using it.

The development of the lesson objectives, the lesson, and the posttest were also strengths in this study. T'welve people spent a total of 147 hours developing and revising the lesson objectives, the lesson, and the posttest. Precautions were taken to develop a lesson appropriate for 
fifth-grade students, at the correct level of difficulty, and directly related to the objectives and the posttest questions. In addition to the lesson, the project teachers were trained in the process of teaching the lesson with and without active participation. The critique and feedback they received helped the consistency from lesson to lesson. Relying on the professional judgment of other specialists built strength into the study. With curriculum specialists, staff development specialists, teachers, and an assistant superintendent involved, problems were anticipated and resolved before the experiment actually started.

Yet another strength of the study was the field test. The field test allowed an opportunity to try out all of the major components of the study. It gave the teachers practice in a classroom setting, and it afforded an opportunity to review and revise the lesson and the posttest prior to the actual experiment. The field test also provided a foreshadowing of the possible outcomes of the statistical results.

The checking for bias survey using video- and audiotapes of each lesson was a built-in precaution to account for any teaching inconsistencies that might introduce contaminating variables. One criticism leveled at educational researchers by Dunkin and Biddle (1974) was that all too often research is not double-checked for inconsistencies. 
The bias survey in this study revealed that the lessons were very consistent.

Probably the greatest strength of this study was the research design. The strength of the design lies in the control which it exercised over relevant validity factors. By using the class as the unit for analysis (treating class means as scores) the design transformed a quasi-experi-mental, intact groups study into a true experimental study, thereby gaining the advantages of an experimental study in controlling internal validity factors. The study was further strengthened by specific efforts aimed at controlling various extraneous variables. All students were instructed and tested with identical procedures in the mornings, between the hours of 9:00 and 11:00; and the project teachers each taught four lessons with two lessons in Treatment I and two lessons in treatment II. The design, therefore, also controlled for bias by controlling for teacher variable.

Random procedures were used. Though the students were not randomly selected, the classes were randomly assigned to both teacher and method. Dates and times for instruction were also assigned at random.

Though there seems to be some controversy about using intact groups for the unit of study, this may be one of the strengths of this study. If results can be validated in typical classrooms, then the likelihood of those findings 
being successfully applied in other public classroom settings would also be strong. However, there are views which oppose the use of intact groups. This topic will be addressed again in the section dealing with possible shortcomings of the study.

\section{Limitations}

Probably the greatest limiting factor of the study was the posttest because it was teacher-constructed and not standardized. Due to the nature of the study and the topic of the lesson, no standardized test was available. The question that is raised deals with the reliability of the test. To find the posttest reliability, a kuder-Richarason estimate of test reliability (KR21) was calculated; the resulting value was 0.59 . This value, an underestimate of the internal consistency of the test, was not considered to be a serious threat to the test validity (the index of validity is the square-root of the reliability coefficient or 0.77 ) or research valiáity. However, a higher reliability coefficient was hoped for. Some unyielding factors contributed to the present one. While the researcher strove to construct a more difficult lesson and test so as to obtain a more normal distribution of scores, the other educators involved with helping to construct the lesson and test were primarily concerned with constructing them at the correct level of difficulty and creating success for the 
student. This is normally a sound eduational practice, except when a test is being constructed for the purpose of being sensitive to change and to accurately measure student learning. The student test scores, therefore, reflected a lesson which was designed for student success. These scores may be the result of the following: (1) The lesson was designed effectively, (2) the teachers taught effectively, (3) the test was not difficult enough to measure the student achievement, and/or (4) the test was too short.

Another shortcoming of this study was the length of the lesson. Though active participation was expected to have an immediate effect, a 30-minute lesson can only be an indicator of its effectiveness over the longer length of time a student spends during a school year. There are reasons to believe, as indicated by Bloom (1976), that active participation would prove to be effective in a longitudinal study; but that supposition still needs empirical evidence.

Though the sample of students was large, the final number for Treatment I (213) was slightly smaller than the final number for Treatment II (234). Since not all classes were equal in size and since there was a great deal of absenteeism due to the flu during the experiment, class sizes varied slightly. This, however, according to Ellis (1975, page 126) and Richmond (1964, page 194) does not make 
a significant difference in relatively large samples.

Another perceived shortcoming to some was the use of intact groups and the use of class means rather than individual students' scores as units of measure. The recent article by Hopkins (1982), "The Unit of Analysis: Group Means Versus Individual Observations," addressed this very point. Hopkins indicated that results obtained by group means are not rich, are unduly restrictive, may not account for nested results, and limits the questions that can be asked in a study. Though Hopkins (1982) builds a strong case for individual scores for the unit of analysis, he still said that "confusion is still evident" (page 6). Hopkins quoted Glass and Stanley (1970) who maintain that a potentially illegitimate study can be done when using the individual as the unit of analysis yet a legitimate study can be run by using class means. Glass and Stanley said that it is likely that no statistically significant results will be found. Kempthrone, as reported by Hopkins said:

If all experimental units receiving each particular treatment receive it together,...the only conclusion about any treatment difference observed is that it is attributable to the way of teaching or the instructor or partly due to each. (p 8)

Ellis (1975) and Ebel (1972) have both discussed the use of group means as acceptable approaches as the unit of analysis. The question of nested effects, however, remains unanswered for this study. 
The results of this study suggest that active participation does make a difference in learning as measured by an immediate posttest. However, it would be interesting to retest the students in Treatment I and Treatment II after a delay of one or two months, to see if the learning differentiated over an extended time perioä.

\section{Implications for the Classroom}

The findings of this study have some implications for the classroom. It is important to remember that active participation was a part of Hunter's application of theory into practice. It is also important to know where active participation fits in instruction and how it is used. First, Hunter suggests that the teacher know how to teach to an objective with behaviors and information appropriate to the objective. Then Hunter talks about selecting objectives at the correct Level of difficulty, and then monitoring and adjusting the progress of the student through the lesson. With this foundation the teacher can begin to apply the principles of learning (among which is active participation). This study appears to confirm that active participation is effective. However, it should be noted that it may be effective only after the teacher has other lesson components in place, such as teaching to an objective and selecting that objetive at the correct level of difficulty. This has implications for all classrooms because teachers 
must have skills in lesson planning and in diagnosing students. Then, when used correctly, active participation provides a focal point for learning. BY using active particpation and asking that the students overtly respona, the teacher has involved the students in thinking, writing, aescribing, or identifying. Active participation also provides practices for the student which gives the teacher teedback for monitoring and adjusting. In addition, active participation provides in-class time on task. The implications for the teacher are for spending less time lecturing and more time having students demonstrate what they can or cannot do, based on the information the teacher has given the class.

School administrators must begin to bear some of the burden of responsibility for teacher training. A welltrained and educated teacher does not develop in four undergraduate years. Administrators have a responsibility for staff renewal, up-grading of skills, and introducing new ideas and techniques to teachers. Active participation, along with other researched methods, can be incorporated in staff development programs for teachers and used to help improve instruction at the classroom level.

\section{Implications for Research}

This study suggests further research. Some areas suggested for study are (1) retention over time and (2) the 
longitudinal effects of active participation in the classroom.

Mechner (1967) said that the older, all-inclusive theories were gone as major forces, Brophy (1979) said that small studies should be conducted in classroom settings and Dunkin and Biddle (1974) said that research in these areas is not well established. This study was an attempt to deal with one aspect of instruction in a classroom setting. With additional studies, educators may begin to formulate a sound theory of instruction.

In the interest of gaining more knowledge and understanding about active participation as an instructional method, this study should be replicated. A study with a series of three posttests over time would also begin to answer what effect active participation has on retention and would answer the question of whether or not active participation has an immediacy feature that may make it effective temporarily but not over time. Another recommendation is that a similar study be conducted with older students. It may be possible that the effectiveness of active participation varies with the age of the student.

\section{Summary}

The primary purpose of this study was to investigate whether or not the use of active participation by teachers 
can make a difference in the learning of their students. Specifically, the research hypothesis was that classes taught with active participation would achieve more--as measured by an immediate posttest--than would classes taught without active participation.

An experiment involving 437 fifth-grade students in a middle-sized school district was conducted. The research design was a comparison-group design with two treatment levels--active pareticipation and non-active participation. The design compared the means of class means for both treatments. An independent $t$-test was calculated.

It was found that the calculated-t surpassed the critical-t, therefore, leading to a rejection of the statistical hypothesis. The research hypothesis was accepted, suggesting that active participation is an effective method for instruction. It would appear that, when a teacher correctly employs active participation in instruction, the likelihood is that students' learning will be improved. In related studies by McDonald (1976) and Evertson (1978), where students were more directly participating in a teacher-dominated activity, similar findings were produced. The recommendation of this investigator is to employ the use of active participation in classrooms as one means of improving instruction. 


\section{BIBLIOGRPAHY}

Anderson, Edwin R. Personal inquiry in the classroom: An alternative approach to educational research. Seattle, Washington: University of Washington, 1975. (ERIC Document Reproduction Service, ED 111 789)

Bennett, S. N. Recent research on teaching: A dream, a belief and a model. British Journal of Educational

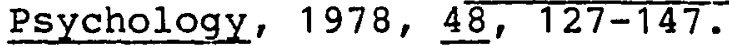

Berliner, David $C$. The California beginning teacher evaluation study: Overview of the Ethnographic study. Journal of Teacher Eaucation, 1976a, 27(1), 24-30.

Experimental teaching units and the identification of a special sample of classrooms for conducting research of teaching. Washington, D.C., 1976b. (ERIC Document Reproduction Service, ED 147 278)

Blishen, Edward, (Ed.) Encyclopedia of Education. New York: Philosophical Library, 1970 .

Block, James H. Mastery learning: Theory and practice. New York; Holte, Rinehart and Winston, Inc., 1971.

Bloom, Benjamin S. Human characteristics and school learning. New York: McGraw Hill, 1976.

Brophy, Jere E. Training teachers in experiments: Considerations relating to nonlinearity and context effects. New York: University of Chicago, 1977. (ERIC Document Reproduction Service, ED 150201 )

Advances in teacher effectiveness research, Paper presented at the annual meeting of the American Association of Colleges of Teacher Education. Chicago: $1979 a$.

Teacher behavior and its effects. Washington D.C.: University of Chicago, 1979b. (ERIC Document Reproduction Service, E'D 181 014) 
Brophy, J.E. and Evertson, C. Student characteristics and teaching. New York: Longman, 1981 .

Brophy, J.E. and Good, T. Teacher-student relationships: Causes and consequences. New York: Holt, Rinehart, and winston, Inc., 1974.

Bugbee, Mary. Experimental shifting of teaching modes in preschool. Tampa, Florida: 1974 (ERIC Document Reproduction Service, ED 196014 )

Butts, Freeman R. ana Cremin, Lawerence. A history of education in American culture. New York: Holt Co., 1953.

Coleman, James S. Equality of educational opportunity. Washington, D.C.: Office of Education (HEW), U.S. Government Printing Oftice, 1966.

Cronbach, Lee J. The two discipiines of scientific psychology. Anierican Psychologist, 1957, 12, 671-684.

Dewey, John. Democracy and Education. New York: The Macmillan Co., 1916.

Doyle, walter. The tasks of teaching and learning in Classrooms. Washington, D.C.: Unviersity of Texas; 1979. (ERIC Document Reproduction Service, ED 185, 069)

Dunkin, Michael J. and Biddle, Bruce J. The study of teaching. New York: Holt, Rinehart, and winston, Inc., 1974.

Ebel, Robert L., ed. Encyclopedia of educational research, Fourth Edition. Toronto, Ontario, Canada: Project of the American Research Association, McMillan Corp., 1969.

Essentials of educational measurement. Englewood Cliffs, N. J.: Prentice-Hall, Inc., 1972.

Ekstrom, Ruth B. Relationships between teacher aptitudes, teaching behaviors, and pupil outcomes. Chicago: Otíice of Education (HEW), 1978. (ERIC Document Reproduction Service, ED 156 621)

Elias, Patricia; and Wheeler, Patricia. Instructional activities as reported by teachers, Journal of Teacher Equcation, 1976, 27(4), 326-328. 
Elliot, John. Developing hypothesis about classrooms from teachers' practical constructs: An account of the work of the Ford teaching project. Interchange, 1976, $7(2), 2-22$.

Ellis, Richard B. Statistical inference. Hoverhil1, Mass.: Prentice-Hall, Inc.r.1975.

Evertson, Carolyn M. Texas junior high school study: Final report of process-outcome relationships. Michigan: Michigan University, 1978. (ERIC Document Reproduction Service, Ed 173744 )

Fedigan, Larry. School-based elements related to achievement. Edmonton, Alberta, Canada: Alberta Department of Education, 1979. (ERIC Document Reproduction Service, ED 181043 )

Fitz-Gibbon, C. and Morris, L. How to calculate statistics. Beverly Hills, California: Sage Publications, 1978.

Gallup̀, George. Gallup Poll. Phi Delta Kappan, 1978, 60:1, 33-45.

Glass, Gene V. and Smith, Mary L. Class size research: A critique of recent meta-analyses. Phi Delta Kappan, $1980,62(4), 239-244$.

Glass, Gene V. and Stanley, Julian C. Statistical methods in education and psychology. Englewood Cliffs, N.J.: Prentice-Hall, Inc., 1970.

Glasser, Robert. The design of instruction. In the Changing American School 65th Yearbook, Part II, NSSE: University of Chicago Press, 1966, 215-242.

Good, Thomas; Biddle, Bruce; and Brophy, Jere. Teachers make a difference. New York: Holt, Rinehart, and winston, 1975 .

Hickman, Janet. Extending the dimensions of research in response to literature: Response in an elementary school setting. Columbus, Ohio: Ohio State University, 1980. (ERIC Document Reproduction Service, ED 189 600)

Hopkins, Kenneth. The unit of analysis: Group means versus Individual Observations, American Educational Research Journal, 1982, 19(1), 5-18.

Hunter, Madeline C. Improved instruction. El segundo, California: Theory Into Practice (TIP) Publications, 1976. 
Hutt, S. J. and Hutt, C. Direct observation and measurement of behavior, Springfield, Illinois: C. H. Thomas, 1970 .

Koppelman, Kent. The relationslhip of cognitive style to teaching style. Toledo, onio: (Midwest Educational Research Association, 1980. (ERIC Document Reproduction Service, ED 194 609)

Levin, Henry. Educational planning and teaching-learning strategies: The notes of a skeptic. Paris, France: U.S. Educational, Scientific ana Cultural Organization, 1977, (ERIC Document Reproduction Service, ED $179006)$

McDonaid, Frederick J. Report on phase II of the beginning teachers' evaluation study, Journal of Teacher Education, $1976,17(1), 39-4 \overline{2}$.

Marshall, Jon C. and Hales, Loyde W. Classroom test construction. Reading, Mass.: Addison-Wesley, 1971.

Mayhew, Katherine Camp and Edwards, Ann Camp. The Dewey School. New York: Äntherton Eress, 1966.

Measel, Wes and Mood, Darlene $W$. Teacher verbal behavior and teacher and pupil thinking in elementary school. Journal of Educational Research, 1972, 66(1), 99-102.

Mechner, Francis. Behavioral Analysis and Instructional sequencing. In Programmed Instruction, 66th Yearbook, Part II, NSSE: University of Chicago Press, 1967, $81-103$.

Medley, Donald M. Assessment and research in teacher education: Focus on PBTE. washington, D.C.: Association of Colieges for Teacher Education, 1975.

Teacher competence and teacher effectiveness. Washington, D.C.: Association of Colleges of Teacher Education, 1977.

Morgan, Daniel P. Relationship between learner characteristics and instructional methods in a special education mini-course on individualized instruction. (Doctoral dissertation, Elorida State University, 1976).

Parakh, Jal s. Some reflections and perspectives on the stuajy of teaching. Science Education, 1971, 5ㄷ⑵, $171-175$. 
Ray, william S. Statistics in psychology research. New York: McMillan Co., 1962.

Richmond, Samuel B. Statistical analysis, Second Edition. New York: Ronald Press, 1964 .

Rosenshine, B. V. Recent research on teaching behaviors and student achievement. Journal of Teacher Education, $1976,17,61-65$.

scott, Myrtle. Some parameters of teacher effectiveness as assessed by an ecological approach. Washington, D.C.: Division of Educational Labs: 1969. (ERIC Document Reproduction Service, ED 177 156)

Silvernail, David. Teaching styles as related to student achievement: What research say to the teacher. Washington, D.C.: Department of Education (HEW), 1979. (ERIC Document Reproduction Service No. ED 177 $156)$

Skinner, B.F. The Behavior of organisms: An experimental analysis. New York: Appleton, 1938

Soar, Robert S. A measure of teacher classroom management. Gainesville, Florida: Bureau of Elementary and Secondary Education, 1971. (ERIC Document Reproduction Service, ED 157890 )

Teacher behavior related to pupil growth. International Review of Education. $1972,18(4), \frac{1}{201-2} 14$.

Soar, Robert S, and Soar, Ruth. An attempt to identify measures of effectiveness from four studies. San Francisco, California: American Educational Research Association, 1976. (ERIC Document Reproduction Service, ED 121854 )

Travers, Robert M. (Ed.). Second hanabook of research in teaching. Project of the American Educational Research Association. Chicago, Illinois: Rand McNally, Chicago Publishing Co., 1973.

Westcott, Wayne L. Effects of teacher modeling on the subsequent behavior of students. (Doctoral dissertation, Ohio State University, 1978). Dissertation Abstracts International, $1978,38,66 \overline{05 A}$. 
Appendix A

Lesson Plan 
Lesson Plan

PROBABILITY LESSON PLAN - (with ACTIVE PARTICIPATION)

SET - In the past, there have probably been times when you wanted to know the likelihood of something happening say for example, the chance of winning a prize in a drawing or raffle or the chances of rolling a certain number on the dice in a game. Well today, we are going to study about how to figure out your chances of something happening. We call that subject probability.

Topic: Simple Probability

Terminal objective: The students will be more precise about making predictions by writing predictions in a mathematical ratio.

Specific Lesson Objectives:

1. The learner will be able to define probability.

2. The learner will be able to know and explain the meaning of a mathematical probability ratio.

3. The learner will be able to forumulate a probability ratio based on an observation.

4. The learner will be able to read a probability ratio.

5. The learner will be able to predict the probability of a given event expressed as a ratio.

6. The learner will be able to use data to support predictions.

\section{Purpose:}

The reason we are doing this is that you are often in situations when you want to predict their outcome like in:
a) Find out our chances of being selected as president of your class
b) Find out chance of getting the yellow gum ball if there are 3 reds and 1 yellow left in the
c) Find the chances of our favorite team winning the basketball game 
Objective 1

Recall definition of probability

Transition - Let's now look at a definition for probability

Tell - Transparency - Read with me

"The chance of something happening"

Use examples in purpose statement

Probability is what the chance of my favorite team winning the Super Bowl is or what my chances are of getting a green gumball.

Transition: We can understand this definition better by writing it in a mathematical form.
Say together with and without teacher.

Say to neighbor covert for listener (model behavior) 
Input

Objective 2

Know and understand probability ratio

1. Spinner (transaprency) - show spinner put pencil on transparency.

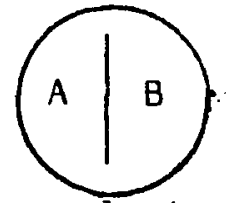

We will now look at what our chance of gettin $A$ is.

\section{$1 / 2$ (teacher answers)}

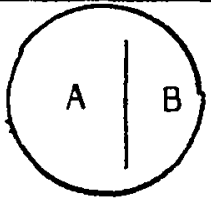

We will now look at what our chance of getting $B$ is.

\section{$1 / 4$ (teacher answers)}

2. Mathematical ratio - (transparency)

We can write using this formula:

(compare with) 非 of chances for a given event $=$ total comes

Example: Use 1 above again (ask question... what is our chance? Then show with formula).

Next example: Jelly Beans Transparency

Spinner - What are our chances of getting $A$ ? Ratio on transparency.
Active Participation

They state the two parts in unison 
Input

Restate ratio

A A

B C

\# of times the event could occur

total 1 of things that could occur

What does the 5 in this ratio mean?

$(5 / 8)$ What does the 8 mean? Write on your paper.
Active Participation

Write down their explanation of the 2 parts and share with neighbor. 
Objective 3

Formulate probability ratio based on an observation

Transparency and TeIl

a) $\mathrm{A} \mid \mathrm{B}$

Spinner lands on A-write a $1 / 2$

State the ratio

b) Transparency

if you flipped a coin 12 times, and heads appeared 3 times, write as a ratio:

$$
\frac{3}{12}
$$

Use formula transparency \& compare

c) Examples for checking

If you had 5 marbles in a bag, 2 were blue and 3 were red, what is the probability ratio?

When you flipped a coin 10 times, you got heads 5 times.

Write the ratio.

Transition - We have formulated ratios for events that have happened. Now let's learn to read ratios.
They write the ratio for c. 
Input

Objective 4

Read Ratio

Transparency \& Model

1. Model

Read the top 非 first, say 3 , then for the next line, you say "chances out of"

Next, read bottom 非, 10 .

$\frac{3}{10} \quad 3$ chances out of 10

$\frac{1}{4} \quad 1$ chance out of 4

Transition - Reading a ratio is something you do well. Let's now learn how. Formulate a probability ratio for an event that has not happened yet.
Active Participation

Read out loud in unison

and then in pairs.

$\begin{array}{llll}\frac{2}{4} & \frac{3}{5} & \frac{1}{3} & \frac{7}{12}\end{array}$

Without the teacher

$\begin{array}{llll}\frac{3}{6} & \frac{4}{9} & \frac{1}{5} & \frac{2}{3}\end{array}$ 
Input

Objective 5

Formulate a probability ratio Model -

\section{a) Spinner (transparency)}

What are the chances of getting an A? Let's write the probability ratio.

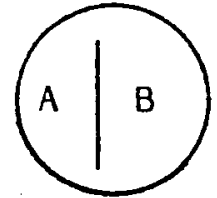

Count how many total outcomes and write the bottom number.

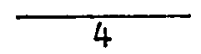

Count the 非 of times the event could occur. Write the top number

$$
\frac{1}{4}
$$

b)
\begin{tabular}{l|l}
$A$ & $B$ \\
$B$ & $C$
\end{tabular}
then
\begin{tabular}{l|l}
$A$ & $A$ \\
$A$ & $B$
\end{tabular}

c) If you were 1 of 3 students nominated for class president, what would your chances be of winning? Write the probability ratio.

$$
\frac{1}{3}
$$

d) There are 5 checkers in a bag, 3 red and 2 black, what are my chances of getting a red?

Transition - Tou now can write a ratio to predict your chances of something happening. Let's now take a look at how to make your predictions more accurate.
Active Participation

They write

They write

Say out loud or hold up fingers. 
Input

Objective 6

Use information to support predictions

I. Go to transparency

(0bj. 6 非 1$)$ make it

tie back to appropriate

ratio.

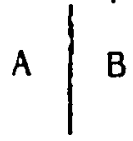

II. Compare to a coin (2 sides) A \& B are like heads and tails.

III. 1. What would you expect if you flipped a coin 20 times?

2. What would you expect if you flipped a coin 10 times.

IV. 1. Go to transparency (0bj. 6 \#2) Look at the chart - just the first 10 flips (cover the rest of the chart)

2. Tabulate results by counting together the number of heads and

V. 1. Look at the remaining flips to 100 - Look at the totals (upper What can we say about (conclude) from what we see? (The more information we have the more accurate predictions can be.
Active Participation

1. Covert A.P. Think! what would expect if ...

2. Covert again Think!....

2. A.P. - counting together the \#1 of tails.

1. A.P. Conclude with partner right hand) 
Input

objective 6 continued

VI. What can we conclude from this information? In making a prediction, would you want a little or a lot of information (data?)

VII. (by the teacher) the more information you have, the more accurate your predictions will be.

Transition - We have covered a lot of information about probability. Let's review each thing we've covered one more time so we don't forget it.

Closure - close on each objective

- define probability

- understand ratio

- etc.

Active Participation

A.P. Raise your hand for little or for a lot of data - Explain to your neighbor why you would want a lot.

Outloud - Unison

Unison - What does Bottom 作 tell us and top \# tell us? Etc. 
Appendix B

Posttest 
Project Lesson Post-Test

Student's name

Date

School

Teacher's name

Sample question: (circle one letter beside the correct answer)

Which animal has 4 legs?
A. Bird
B. Fish
C. Horse
D. Snake
E. Spider

1.) What is the definition of probability?

A. For certin something will happen or the number of total outcomes compared to only certain events

B. The luck you have when something happens

C. The chance of something happening or the number of chances for an event to happen compared with the total number of events

D. Knowing that probably you are taking a chance

E. Making guesses about why something happens

2.) In the probability ratio $2 / 5$, the "2" is the number of :

A. lucky things that will happen

B. things that will happen for certain

C. total possible outcomes

D. outcomes that cannot occur

E. number of chances for an event to happen 
3.) In the probability ratio $5 / 7$, the $7 "$ is the number of:

A. lucky things that will happen

B. things that will happen for certain

C. total possible outcomes

D. outcomes that cannot occur

E. number of chances for an event to happen

4.) How is a proability ratio written?

A. Number of total outcomes Number of chances for an event to happen

B. Number of certain things Number of lucky things

C. Number of times something happens Number of chances for an event to happen

D. Number of chances for an event to happen Number of total outcomes

E. Number of total outcomes Number of guesses

5.) How do you say the probability ratio 3/8?

A. eight chances out of 3

B. three chances into eight

C. three and eight are eleven

D. eleven chances out of eight

E. three chances out of eight

6.) You flipped a coin 10 times and tails appeared 7 times. How would you write the probability ratio?

A. $10 / 7$

B. $7 / 7$ 
c. $10 / 10$

D. $3 / 10$

E. $7 / 10$

7.) There are 20 students in your class and your name is drawn from a hat as a winner. How would you write the probability ratio of this happening?
A. $20 / 1$
B. $1 / 20$
C. $1 / 1$
D. $20 / 20$
E. $2 / 10$

8.) Figure非 1 The spinner in figure 1 was spun once and red appeared. How would you write the probability ratio for this happening?
A. $3 / 4$
B. $4 / 3$
C. $1 / 4$
D. $3 / 3$
E. $1 / 3$

9.) You have a deck of 20 cards and 4 of them are blue. What are your chances of drawing a blue card?
A. 20 chances out of 5
B. 4 chances out of 16
C. 16 chances out of 20
D. 20 chances out of 16
E. 4 chances out of 20 
10.) Figure \#2 What would be a probability ratio of spinning a red on the spinner in figure \#2 with one spin?
A. $3 / 1$
B. $1 / 2$
C. $3 / 3$
D. $1 / 3$
E. $2 / 3$

11.) A gumball machine has 3 red gumballs, 2 yellow gumballs, and 5 green gumballs. What would be your chances of getting a yellow gumball?
A. $2 / 5$
B. $2 / 10$
C. $3 / 10$
D. $10 / 2$
E. $2 / 8$

12.) There are 15 jellybeans in a jar; 11 of them are black and the rest of them are orange. What is the chance of getting an orange jellybean in a single blind draw?
A. $11 / 15$
B. $15 / 4$
C. $4 / 15$
D. $15 / 11$
E. $\quad 4 / 11$ 
13.) Figure \#3 When you spin the spinner in figure \#3 many many times, you would expect that:
A. black and white will appear about the same number of times.
B. black will appear more than white
C. white will appear more than black
D. neither will appear
E. you can guess the exact number of times black will appear.

14.) Figure \#4 When you spin the spinner in figure \#4 ten times, you would expect to have green appear about:
A. 5 times
B. 8 times
C. once
D. never at all
E. everytime

15.) Figure \#5 When you spin the spinner in figure \#5 sixty times, you would expect that.
A. red would appear more than blue
B. blue would appear more than red
C. red and blue would appear about the same number of times
D. neither red nor blue would appear very often
E. blue would never appear 
Appendix C

Bias Criteria 
Class

Date

Time of day

Time duration of lesson

I. Data collection (record by tally the frequency of occurances)

A. What was the number of external Interruptions?

B. What was the number of disruptions by students?

C. How many times did the teacher use pralse?

D. How many times did the teacher vary from the lesson?

E. How many times did the teacher use active particlpation

F. How many times did the teacher use active participation when she should not have?

G. How would you rate the tachers level of enthuslasm? (" 1 " is low and "5" is high) clrcle one: $123 \quad 345$

\section{External factors}

A. Were there unusual classroom interruptions?

Yes $\quad$ No

$\bar{\square}$

Explain Yes

B. Were the weather conditions (snow storm) unusual?

C. Were there any unusual school schedules or events?

D. Did the day of the week (such as Monday, or Friday) seem to cause the students to behave unusually?

E. Was the lesson taught in the afternoon?

F. Did the physical cldssroom environment (placement of desks \& chairs, etc.) seem to make an unsual difference in the teaching of the lesson? 
G. If the homeroom teacher was present, did he/ she seem to af fect the students, lesson, or profect teacher?

H. Did the class size (very large or very small) seem to influence how the lesson was taught?

I. Was the lesson taught in a place other than the student's homeroom?

J. Other (explain?

III. Student factors

A. Did the students' past experience or previous learning seem to influence the lesson in an unusual way?

B. Was the classroom atmosphere unusually hostlle or overtly friendly?

c. Did any students cause abnormal disruptions in the lesson?

D. Was the student behavior as a group abnormal in anyway?

E Other (explain

IV. Teacher factors

A. Did the teacher's past experience seem to influence the lesson in any unusual way

ப ப

B. Did the teacher use a great deal of praise and encouragement?

c. Was the teacher overtly enthusiastic? 
D. Did the teacher do anything out of the ordinary (exhibiting behavior other than what was In the lesson?

E. Did the teacher seem to change his/her style from that exhibited in other lessons?

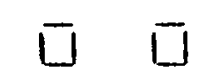

F. Was the management in this lesson much different than that of the teacher in other lessons?

G. Was the teacher's presentation different from that in other lessons?

H. Did the time the teacher took to teach the lesson differ from other lessons?

I. Did the teacher use Actlve Participation when he/she shouldn't have or not used it when they should have?

J. Did the teacher give the students any answers to the test prior to giving the post-test?

K. Other (explain: 
Appendix D

Parent Letter 
Tigard Public Schools, District 23j

February 1982

Dear Parents,

During the later part of February a study will be conducted by Jerry Pratton, Templeton principal in Tigard, jointly between the Tigard Public Schools and Portland State University. Portlnd State is involved through a doctoral dissertation study and the Tigard Public Schools through their instructional improvement program for staff development. The purpose of this is to ascertain the effectiveness of certain methods for instruction.

During the past five years, the Tigard School District has worked to improve teaching through development of a sound system of instruction and through many hours of training our teaching staff. We are at a point where we would like to statistically measure how effective this instruction is. Consequently, that is the focus of the study.

The study involves all fifth grade students in all of the Tigard schools. A typical thirty-minute fifth grade lesson related to the existing curriculum will be taught by Tigard teachers using the type of methods we have been training all Tigard teachers in for the past five years. At the end of the lesson a brief ten item quiz will be administered to see how well the students learned what was taught. The whole process will only happen once and will take less than an hour in the students home room classroom. 
This study project has the support of the school board; the superintendent, Mr. Fennell; the assistant-superintendent of instruction and curriculum, Mr. Taylor; the staff development director, Mrs. Combs; each of the building principals; and of course the project teachers who are involved. The results of the study will surely help us better evaluate our instructional methods and assist us in our continuing process of improvement of teaching.

If you have any questions or comments, your building principals or myself would be happy to answer them. As parents of a fifth grade student involved in the study, we thank you for your support and cooperation.

Respectfully,

Jerry D. Pratton, Principal Templeton Elementary School 
Appendix $E$

Observation of Bias Survey

Treatment I 
Observation Results of Bias Criteria

Survey for Treatment I

\begin{tabular}{lllllllllllllll}
\multicolumn{10}{c}{ Classes } \\
\hline Factors & 1 & 2 & 3 & 4 & 5 & 6 & 7 & 8 & 9 & 10 & Totals & Mean
\end{tabular}

Tallied Data

$\begin{array}{lrrrrrrrrrrrr}\text { A } & 0 & 1 & 1 & 0 & 2 & 0 & 1 & 0 & 0 & 3 & 8 & .800000 \\ \text { B } & 0 & 0 & 2 & 1 & 1 & 0 & 2 & 2 & 0 & 0 & 8 & .800000 \\ \text { C } & 13 & 14 & 15 & 13 & 11 & 16 & 14 & 18 & 18 & 17 & 147 & 14.700000 \\ \text { D } & 1 & 0 & 0 & 0 & 1 & 0 & 0 & 0 & 0 & 0 & 2 & .200000 \\ \text { E } & 59 & 61 & 63 & 60 & 56 & 58 & 62 & 59 & 61 & 61 & 600 & .200000 \\ \text { F } & 0 & 0 & 0 & 0 & 0 & 0 & 0 & 0 & 0 & 0 & 0 & 0.000000 \\ \text { G } & 3 & 3 & 3 & 3 & 2 & 2 & 3 & 2 & 4 & 4 & 29 & 2.900000\end{array}$

External Factors

\begin{tabular}{|c|c|c|c|c|c|c|c|c|c|c|c|c|}
\hline A & $N$ & $N$ & $N$ & $N$ & $N$ & iv & $N$ & $\mathrm{~N}$ & $N$ & $Y$ & 1 & .100000 \\
\hline$B$ & $N$ & $N$ & $N$ & $N$ & $N$ & $N$ & $N$ & $N$ & $\mathrm{~N}$ & $N$ & 0 & 0.000000 \\
\hline c. & $N / A$ & $N$ & $\mathrm{~N}$ & $N / A$ & $N$ & $\mathrm{~N}$ & $N$ & $N$ & $N$ & $N$ & 0 & 0.000000 \\
\hline D & $N$ &.$N$ & $N$ & $N$ & $N$ & $N$ & $N$ & $N$ & $N$ & $N$ & 0 & 0.000000 \\
\hline$E$ & $N$ & $N$ & $N$ & $N$ & $N$ & $N$ & $N$ & $N$ & $N$ & $N$ & 0 & 0.000000 \\
\hline$F$ & $N$ & $N$ & $N$ & $N$ & $N$ & $N$ & $N$ & $N$ & $N$ & $N$ & 0 & 0.000000 \\
\hline G & $N$ & $N$ & $N$ & $N$ & $N$ & $N$ & $N$ & $N$ & $N$ & $N$ & 0 & 0.000000 \\
\hline$H$ & $N$ & $N$ & $N$ & N & $N$ & $N$ & $N$ & $N$ & $N$ & $N$ & 0 & 0.000000 \\
\hline I & $N$ & $N$ & $N$ & $N$ & $N$ & $N$ & $N$ & $N$ & $\mathrm{~N}$ & $N$ & 0 & 0.000000 \\
\hline
\end{tabular}

Student Factors

$\begin{array}{llllllllllllr}A & N & N & N & N & N & N & N & N & N & N & 0 & 0.000000 \\ B & N & N & N & N & N & N & N & N & N & N & 0 & 0.000000 \\ C & N & N & N & N & N & N & N & \text { N } & \text { N } & \text { N } & 1 & .100000 \\ S & N & N & N & N & N & N & N & N & N & N & 0 & 0.000000\end{array}$

Teacher Factors

\begin{tabular}{|c|c|c|c|c|c|c|c|c|c|c|c|c|}
\hline A & $N$ & $N$ & $N$ & $N$ & N & $N$ & $N$ & $N$ & $N$ & N & 0 & 0.000000 \\
\hline B & $N$ & $N$ & $N$ & $N$ & $N$ & $N$ & $N$ & $N$ & $N$ & $N$ & 0 & 0.000000 \\
\hline C & $N$ & N & $N$ & N & $N$ & $N$ & $N$ & $N$ & $\mathbf{N}$ & $N$ & 0 & 0.000000 \\
\hline D & $N$ & $N$ & $N$ & $N$ & $N$ & $N$ & $N$ & $N$ & $N$ & $\mathrm{~N}$ & 0 & 0.000000 \\
\hline$E$ & $N$ & $N$ & $N$ & $N$ & $N$ & $N$ & $N$ & $N$ & $N$ & $N$ & 0 & 0.000000 \\
\hline$F$ & $N$ & $\mathrm{~N}$ & $N$ & N & $N$ & $N$ & $N$ & $\mathbf{N}$ & $N$ & $N$ & 0 & 0.000000 \\
\hline G & $N$ & $N$ & $N$ & $N$ & $N$ & $\mathbf{N}$ & $N$ & $N$ & $N$ & $N$ & 0 & 0.000000 \\
\hline H & - & - & - & - & - & - & - & - & - & - & - & $\cdots$ \\
\hline I & $\mathrm{N}$ & $N$ & $N$ & $N$ & $N$ & $N$ & $N$ & $N$ & $\mathbf{N}$ & $N$ & 0 & 0.000000 \\
\hline 了 & $N$ & $N$ & $\mathbf{N}$ & $\mathbf{N}$ & $\mathbf{N}$ & $N$ & $\mathrm{~N}$ & $\mathbf{N}$ & $N$ & $\mathbf{N}$ & 0 & 0.000000 \\
\hline
\end{tabular}

*N $=$ No observed blas

$Y=$ Yes observed bias 
Appendix $F$

Observation of Bias Survey

Treatment II 
Observation Results of Blas Criteria

Survey for Treatment II

\section{Classes}

\begin{tabular}{llllllllllllll}
\hline Factors & 1 & 2 & 3 & 4 & 5 & 6 & 7 & 8 & 9 & 10 & Totals & Mean \\
\hline
\end{tabular}

$\frac{\text { Tallied Data }}{A}$

$\begin{array}{lrrrrrrrrrrrr}\text { A } & 2 & 0 & 0 & 0 & 1 & 0 & 1 & 0 & 0 & 4 & 8 & .400000 \\ \text { B } & 0 & 1 & 0 & 0 & 0 & 2 & 0 & 0 & 0 & 3 & 8 & .300000 \\ \text { C } & 14 & 15 & 17 & 14 & 11 & 12 & 16 & 14 & 17 & 19 & 149 & 14.900000 \\ \text { D } & 0 & 0 & 0 & 0 & 1 & 0 & 0 & 0 & 0 & 0 & 1 & .100000 \\ \text { E } & 0 & 0 & 0 & 0 & 0 & 0 & 0 & 0 & 0 & 0 & 0 & 0.000000 \\ \text { F } & 1 & 0 & 1 & 2 & 3 & 1 & 0 & 1 & 0 & 0 & 9 & .900000 \\ \text { G } & 3 & 3 & 3 & 3 & 2 & 2 & 2 & 3 & 4 & 4 & 29 & 2.900000\end{array}$

External Factors

$\begin{array}{lllllllllllll}\text { A } & \text { N } & \text { N } & \text { N } & \text { N } & \text { N } & \text { N } & \text { N } & \text { N } & \text { N } & \text { N } & 0 & 0.000000 \\ \text { B } & \text { N } & \text { N } & \text { N } & \text { N } & \text { N } & \text { N } & \text { N } & \text { N } & \text { N } & \text { N } & 0 & 0.000000 \\ \text { C. } & \text { N } & \text { N } & \text { N } & \text { N } & \text { N } & \text { N } & \text { N } & \text { N } & \text { N } & \text { N } & 0 & 0.000000 \\ \text { D } & \text { N } & \text { N } & \text { N } & \text { N } & \text { N } & \text { N } & \text { N } & \text { N } & \text { N } & \text { N } & 0 & 0.000000 \\ \text { E } & \text { N } & \text { N } & \text { N } & \text { N } & \text { N } & \text { N } & \text { N } & \text { N } & \text { N } & \text { N } & 0 & 0.000000 \\ \text { F } & \text { N } & \text { N } & \text { N } & \text { N } & \text { N } & \text { N } & \text { N } & \text { N } & \text { N } & \text { N } & 0 & 0.000000 \\ \text { G } & \text { N } & \text { N } & \text { N } & \text { N } & \text { N } & \text { N } & \text { N } & \text { N } & \text { N } & \text { N } & 0 & 0.000000 \\ \text { H } & \text { N } & \text { N } & \text { N } & \text { N } & \text { N } & \text { N } & \text { N } & \text { N } & \text { N } & \text { N } & 0 & 0.000000 \\ \text { I } & \text { N } & \text { N } & \text { N } & \text { N } & \text { N } & \text { N } & \text { N } & \text { N } & \text { N } & \text { N } & 0 & 0.000000\end{array}$

Student Factors

$\begin{array}{llllllllllllr}\text { A } & N & N & N & N & N & N & N & N & N & N & 0 & 0.000000 \\ B & N & N & N & N & N & N & N & N & N & N & 0 & 0.000000 \\ C & N & N & N & N & N & N & N & Y & N & N & 2 & .200000 \\ S & N & N & N & N & N & N & N & N & N & N & 0 & 0.000000\end{array}$

Teacher Factors

\begin{tabular}{lllllllllllll}
$A$ & $N$ & $N$ & $N$ & $N$ & $N$ & $N$ & $N$ & $N$ & $N$ & $N$ & 0 & 0.000000 \\
$B$ & $N$ & $N$ & $N$ & $N$ & $N$ & $N$ & $N$ & $N$ & $N$ & $N$ & 0 & 0.000000 \\
$C$ & $N$ & $N$ & $N$ & $N$ & $N$ & $N$ & $N$ & $N$ & $N$ & $N$ & 0 & 0.000000 \\
$D$ & $N$ & $N$ & $N$ & $N$ & $N$ & $N$ & $N$ & $N$ & $N$ & $N$ & 0 & 0.000000 \\
$E$ & $N$ & $N$ & $N$ & $N$ & $N$ & $N$ & $N$ & $N$ & $N$ & $N$ & 0 & 0.000000 \\
$F$ & $N$ & $N$ & $N$ & $N$ & $N$ & $N$ & $N$ & $N$ & $N$ & $N$ & 0 & 0.000000 \\
$G$ & $N$ & $N$ & $N$ & $N$ & $N$ & $N$ & $N$ & $N$ & $N$ & $N$ & 0 & 0.000000 \\
$H$ & - & - & - & - & - & - & - & - & - & - & - & $-0-0$ \\
$I$ & $N$ & $N$ & $N$ & $N$ & $N$ & $N$ & $N$ & $N$ & $N$ & $N$ & 0 & 0.000000 \\
J & $N$ & $N$ & $N$ & $N$ & $N$ & $N$ & $N$ & $N$ & $N$ & $N$ & 0 & 0.000000 \\
\hline
\end{tabular}

*N $=$ No observed bias

$Y=$ Yes observed bias 